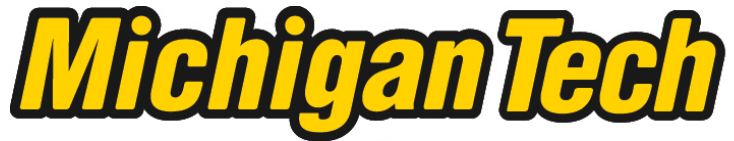 \\ Michigan Technological University Create the Future Digital Commons @ Michigan Tech
}

2013

\section{The Effects of Black Locust (Robinia pseudoacacia L.) on Understory Vegetation and Soils in a Northern Hardwood Forest}

Keri A. Deneau

Michigan Technological University

Follow this and additional works at: https://digitalcommons.mtu.edu/etds

Part of the Ecology and Evolutionary Biology Commons

Copyright 2013 Keri A. Deneau

\section{Recommended Citation}

Deneau, Keri A., "The Effects of Black Locust (Robinia pseudoacacia L.) on Understory Vegetation and Soils in a Northern Hardwood Forest", Master's Thesis, Michigan Technological University, 2013.

https://doi.org/10.37099/mtu.dc.etds/613

Follow this and additional works at: https://digitalcommons.mtu.edu/etds

Part of the Ecology and Evolutionary Biology Commons 
THE EFFECTS OF BLACK LOCUST (ROBINIA PSEUDOACACIA L.) ON UNDERSTORY VEGETATION AND SOILS IN A NORTHERN HARDWOOD FOREST

By

Keri A Deneau

\begin{abstract}
A THESIS
Submitted in partial fulfillment of the requirements for the degree of MASTER OF SCIENCE

In Forest Ecology and Management
\end{abstract}

MICHIGAN TECHNOLOGICAL UNIVERSITY

2013

(C) 2013 Keri A. Deneau 

This thesis has been approved in partial fulfillment of the requirements for the Degree of MASTER OF SCIENCE in Forest Ecology and Management.

School of Forest Resources and Environmental Science

Thesis Co-Advisor: Dr. Linda Nagel

Thesis Co-Advisor: Dr. Jörg Brunet

Committee Member: Dr. Andrew Storer

Committee Member: Dr. Susan Martin

School Dean: Dr. Terry Sharik 

To those that supported me along the way. 



\section{Table of Contents}

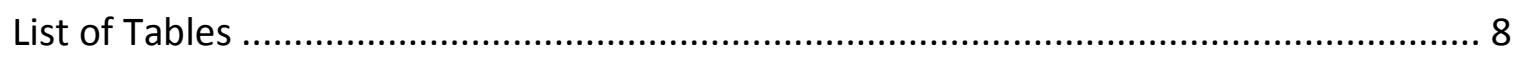

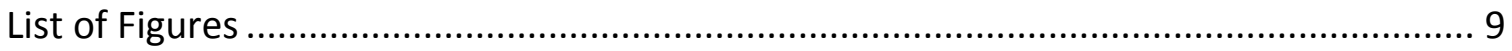

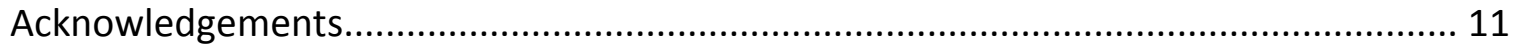

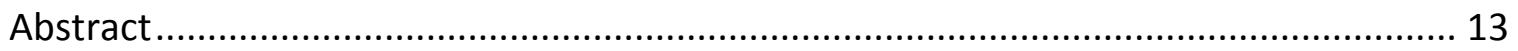

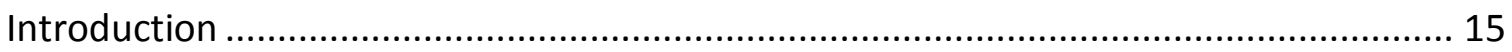

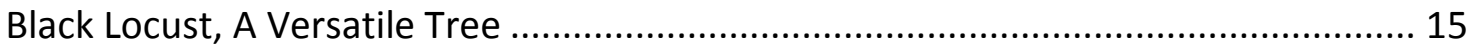

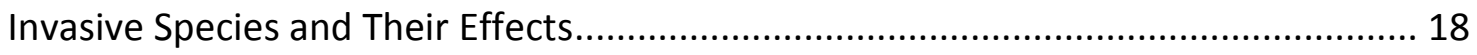

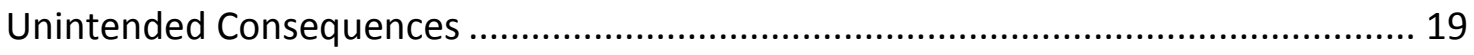

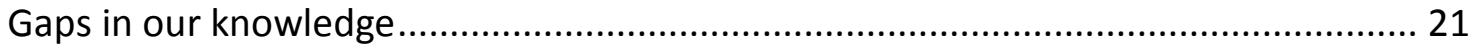

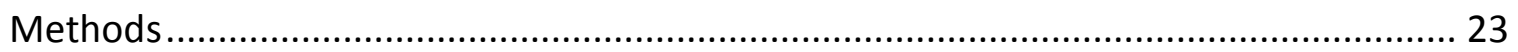

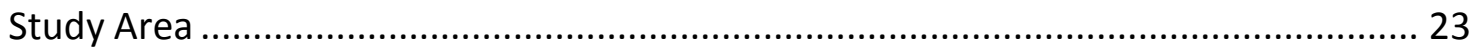

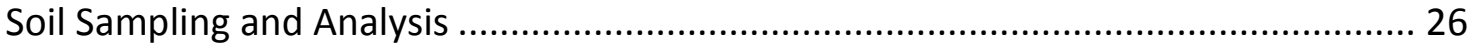

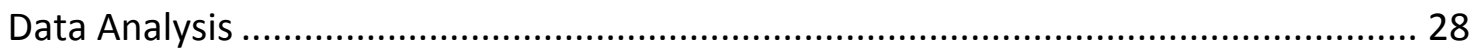

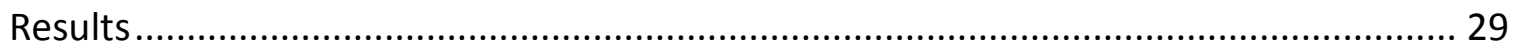

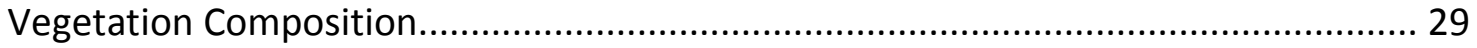

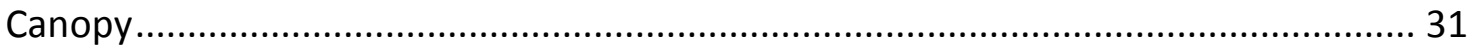

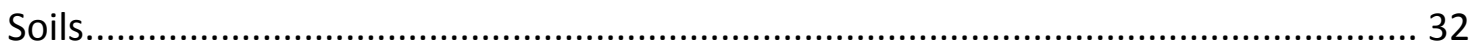

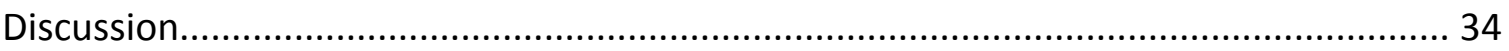

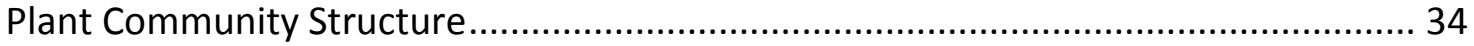

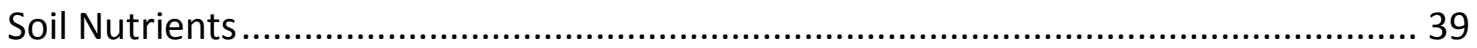

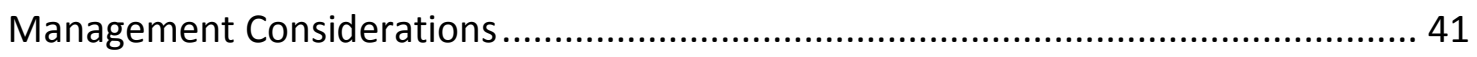

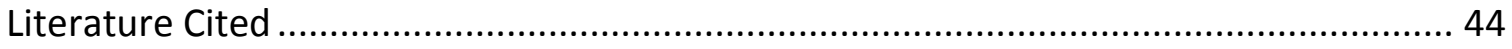

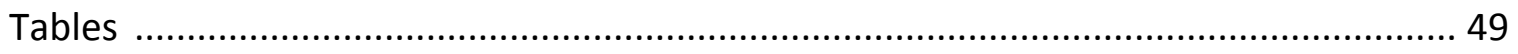

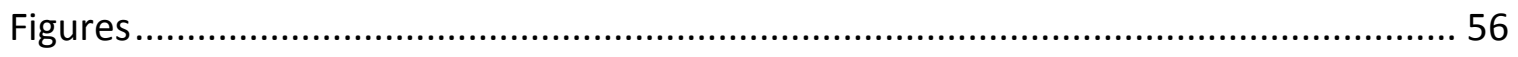

Appendix I: A Brief History: Settlement of the Sleeping Bear Dunes Region .................. 67

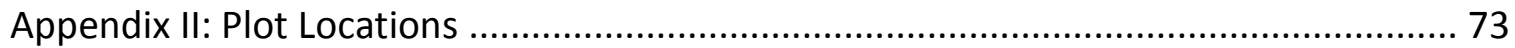

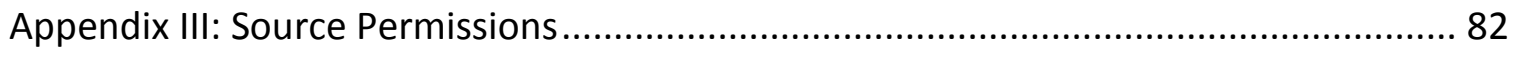




\section{List of Tables}

Table 1: Species richness by plot, broken down by native and exotic species.............. 49

Table 2: Observed understory species for each sampling site.................................... 50

Table 3: Average species richness, Shannon's diversity index, and evenness for all forest vegetation layers ( \pm one SE) for black locust and native hardwood forest stands.

Table 4: Overstory basal area $\left(\mathrm{m}^{2} / \mathrm{ha}\right)$ by tree species for paired black locust and native hardwood plots by site.

Table 5: A summary of primary vegetation measurements, including average basal area, tree counts, quadratic mean diameter, and percent canopy closure ( \pm one SE) for black locust and native hardwood stands.

Table 6: Results of the soil nutrient analysis. 55 


\section{List of Figures}

Figure 1: Native range of Robinia pseudoacacia, the black locust tree. 56

Figure 2: Map of study location, Sleeping Bear Dunes National Lakeshore, Michigan.

Figure 3: Soil core sample, illustrating visual cues used to separate soil layers (red arrows). 58

Figure 4: Understory species richness between black locust and native hardwood sample sites, separated by woody tree species, herbaceous species, and total species combined. 59

Figure 5: Box and whisker plot for percent organic carbon found in top, middle, and bottom visual soil horizons for black locust (BL) and native hardwood (HW) stands.

Figure 6: Percent total nitrogen concentrations found in visual soil horizons at black locust (BL) and native hardwood (HW) stands.

Figure 7: Range of soil potassium concentrations $(\mathrm{mg} / \mathrm{L}$ ) for soil layers in black locust (BL) and native hardwood (HW) stands.

Figure 8: Magnesium concentrations in top, middle, and bottom soil layers in black locust (BL) and native hardwood (HW) dominated stands.

Figure 9: Concentration of calcium in top, middle, and bottom soil layers of the black locust $(\mathrm{BL})$ and native hardwood $(\mathrm{HW})$ stands.

Figure 10: Aluminum concentrations in the soil layers of black locust (BL) and native hardwood (HW) stands.

Figure 11: Differences in cover and light availability under black locust canopy (left) and native hardwood canopy (right) on June 22, 2011

Figure 12: Comparison of homestead locations (1863-1923) within the Sleeping Bear Dunes National Lakeshore area and locations of known invasive tree infestations. 71

Figure 13: Aerial image of the Shell Lake plots. 


\section{List of Figures (continued)}

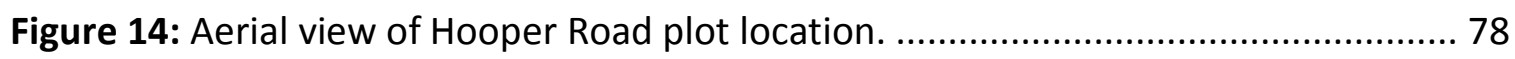

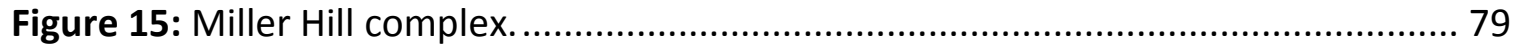

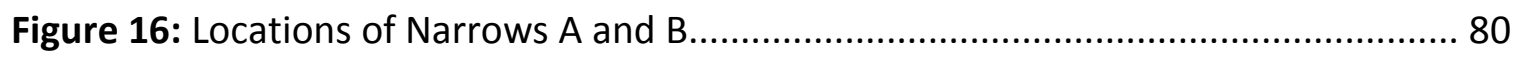

Figure 17: 677 location, one large black locust stand with evidence of

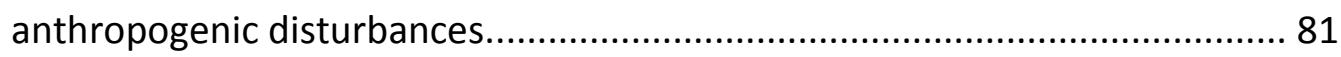




\section{Acknowledgements}

I would like to thank all the people associated with the ATLANTIS program, sponsored by the United States and the European Union for allowing me this wonderful opportunity to expand my horizons and gain both life and academic skills.

I am grateful for the guidance of my advisors, Dr. Linda Nagel in the U.S. and Dr. Jörg Brunet in Sweden. Their time and support during my graduate studies has been extensive and their answers to my numerous questions have been plenty. I would also like to extend my gratitude to my committee members, Dr. Andrew Storer and Dr. Susan Martin, for their assistance in forming this project.

My thanks to Dr. Andrew Burton, for letting me use his equipment and lab for soil preparations; my thanks to Jennifer Eikenberry as well, for not only directing the soil analyses but also altering the sample sizes while I was away.

I would like to thank the wonderful employees at Sleeping Bear Dunes National Lakeshore, for their help and partnership with me through the years. This project was inspired by their mission to improve the natural environment for the enjoyment of all.

My thanks to Paul Gerhart for helping me collect data in the field. I would also like to thank Jennifer Chaffin for her endless motivation, Anna Hess for helping me escape town, and my friends at Old CW's Clan for helping me keep my sanity during the whole process. 
I would also like to extend my appreciation to all my friends and colleagues at Michigan Tech and around the world, my graduate experience has allowed me to make numerous new connections, friendships, and relationships, the encouragement l've received has been overwhelming.

Finally, I would have never been able to complete my studies without the support of my parents, for their encouragement and faith, I am eternally grateful.

Thank you. Kiitos. Tack. 


\section{Abstract}

The nitrogen-fixing tree Robinia pseudoacacia (black locust) has been identified as a potential invasive species outside its native range of the central Appalachian and Ozark Mountains, USA. The objectives of this study were to determine if black locust is causing changes to ground flora and differences in soil nutrient profiles compared to native northern hardwood forests at Sleeping Bear Dunes National Lakeshore (SLBE). Nine pairs of black locust and native hardwood stands were sampled for canopy tree characteristics, ground vegetation cover, and soil nutrients. There were no differences in the ground vegetation assemblages and few differences in the soil nutrient profiles between black locust stands and their native hardwood counterparts. The lack of overall differences, which contradicts findings from other forest ecosystem types, suggests that black locust is altering the northern hardwood forest communities very little at SLBE, a finding that may help guide management decisions. 



\section{Introduction}

\section{Black Locust, A Versatile Tree}

Black locust (Robinia pseudoacacia L.), of the family Fabaceae, is native to the eastern United States and has been introduced to Asia, Africa, Australia, New Zealand, other parts of North America, and in at least 30 countries in Europe (DAISIE, 2006). It is the most widely planted North American tree in the world, and the third most planted tree after hybrid poplar (Populus spp.) and Eucalyptus (DeGomez and Wagner, 2001). Black locust has now become naturalized in most of the temperate regions of the northern hemisphere (DeGomez and Wagner, 2001; Barrett et al, 1990). Its popularity is attributed to several qualities: wide site tolerance, abundant seed crops, fast growth, and high timber and honey yields. It is also excellent for coppicing systems, has seedlings with tremendous rooting ability, and few pests and diseases outside of its native range. As a result, it is sometimes desirable over native species (DeGomez and Wagner, 2001; Kersztesi, 1980).

Black locust was one of the first American trees introduced to Europe in the early $17^{\text {th }}$ century. It was allegedly brought back to France in 1601 for the royal botanical garden (Kersztesi, 1980), although some sources say it was brought to England first (Peabody, 1982). While the exact year and location of introduction to Europe is disputed, the specimen in Jardin des Plantes in Paris was planted in 1636 and survived to the 1980s (Peabody, 1982). By 1710, black locust was being planted and grown in 
Hungary and the practice expanded into Slovakia ten years later (DeGomez and Wagner, 2001).

Black locust is a fast growing, nitrogen-fixing tree native to the hardwood forests of the Appalachian Mountains (Boring and Swank, 1984), from central Pennsylvania and southern Ohio to northeastern Alabama and northern Georgia (Figure 1). A western population exists in the Ozark region of Missouri, extending south into Arkansas and eastern Oklahoma, with additional outlying populations in southern Indiana, Illinois, Kentucky, Alabama, and Georgia (Huntley, 1990). The extent of the original native range is not accurately known, having been successfully planted and naturalized in the contiguous United States (USDA, 2012; Huntley, 1990), reportedly being previously used by Native Americans and then as foundations for buildings in the Jamestown settlement (Virginia, USA) in the $17^{\text {th }}$ century (Sargent, 1892).

Black locust grows in a broad range of forest types and conditions. In its native region, it is a short-term dominant species that encourages early gap formation and forest development (Stone, 2009; Boring and Swank, 1984). It rarely becomes dominant in the canopy with the exception of recently disturbed or early successional communities (Stone, 2009). Black locust is considered a pioneer species, quickly sprouting from roots and stumps, and becomes a dominant tree species after a clearfelling or other major disturbance (Boring and Swank, 1984). It is commonly a component in mature forests but rarely abundant (Huntley, 1990); as individuals 
succumb to competition and stresses, they are replaced in the overstory by shade tolerant and longer-lived species (Boring and Swank, 1984).

Black locust has a long history of use in North America, being spread and used by Native Americans before European settlement (Sargent, 1892). European settlers quickly discovered its uses for fence posts, tree-nails, shipbuilding, and fuelwood, as well as for aesthetics (DeGomez and Wagner, 2001; Michener, 1988; Detwiler, 1937). Early farmers favored black locust to restore eroded and gullied hillsides, improve soil, and provide quality timber on poor soils (Rahmonov, 2009; Michener, 1988; Illinois Farmers' Institute, 1914). They are popular tree species for planting on loose sand (Rahmonov, 2009; Kroodsma, 1937) and mine wastes (DeGomez and Wagner, 2001; Ashby and Baker, 1968), typically where amelioration, erosion control, and reforestation are desired and the soils are poor (Rahmonov, 2009; Stone, 2009; Barrertt et al, 1990).

If not for the damaging effects of the locust borer (Megacyllene robinae), black locust could be one of the most valuable timber species in the United States; unfortunately, the insect bores through the tree, destroying any timber value it might have had (Barrett et al, 1990; Boring and Swank, 1984). Flavonoids in the heartwood of black locust allow the wood to resist decay for over 100 years in the soil (Barrett et al, 1990), high lignin content is responsible for its great strength and durability, and upon drying, shrinks very little (Stone, 2009). It is one of the hardest and most dense woods in North America (Barrett et al, 1990). Other damaging agents to black locust in the United States include other insects, heart-rot fungi, and canker and witches' broom viruses 
(Stone, 2009; DeGomez and Wagner, 2001). The lack of these damaging agents outside of the U.S. has led to wide-spread black locust plantations around the world (Stone, 2009; DeGomez and Wagner, 2001; Kersztesi, 1980).

\section{Invasive Species and Their Effects}

Humans have facilitated the migration of species beyond their natural boundaries, whether by moving a native species to a different region or bringing in a new species from another continent (Mueller and Hellmann, 2008). Cronk and Fuller (1995) define an invasive plant as one that spreads without assistance from humans in natural or semi-natural environments, and in doing so alters ecosystem processes, composition, or structure. Plant invaders can be herbaceous plants, shrubs, or tree species, with trees accounting for approximately ten percent of so called 'weedy' or invasive species (Sutherland, 2003). Plant pests have the potential to disrupt natural systems including disturbance regimes (Mack and D'Antonio, 1998). Most invaders are seen in habitats of high disturbance, with mesic areas being the most invaded during the initial stages of succession (Rejmanek, 1989). These early successional invaders tend to take over disturbed areas by colonizing, growing, and reproducing when competition is greatly reduced (Walker and Smith, 1997).

Through studies of natural and experimental communities, there is a substantive body of evidence that suggests individual species can alter nutrient cycling processes (Castro-Diez et al, 2009; Ehrenfeld et al, 2001; Vitousek and Walker, 1989). Changes in 
the physical properties or soil biota, alterations in species dominance within the system, and modifications in plant functional types are all mechanisms which may drive the alteration of nutrient cycling (Ehrenfeld, 2003). The impact of an invasive species on the system it enters depends on the difference in select key traits between the native and exotic species. These key traits may include reproductive capacity, the ability or inability to fix nitrogen, and growth characteristics (Ehrenfeld, 2003).

Nitrogen-fixing species have a tendency to dominate in secondary successional assemblages, including forests, and can increase nitrogen availability, accelerate the accumulation of nitrogen and organic matter, and ultimately influence the element cycling within the ecosystem (Boring and Swank, 1984). When these species invade a community that does not have a native nitrogen fixer, there can be significant changes to carbon and nitrogen dynamics (Ehrenfeld, 2003) along with species composition (Castro-Diez et al, 2009). In North America, nearly ten percent of invasive species are in the family Fabaceae, known as the legume family (Ehrenfeld et al, 2001). These species are symbiotic nitrogen fixers and have the potential to add significant amounts of nitrogen to the soil, subsequently changing base ecosystem processes (Vitousek, 1990).

\section{Unintended Consequences}

As a result of the broad range of environmental conditions that black locust can adapt to, the pioneer species has become naturalized and even invasive in many areas outside of its native range (Sitzia et al, 2012). Once it is established, black locust can add 
as much as $75 \mathrm{~kg} \mathrm{~N} \mathrm{ha}^{-1}$ a year to the soil (Boring and Swank, 1984) and has a high probability of facilitating other invasive species (Van Holle et al, 2006; Peloquin and Hiebert, 1999). In central and western Europe it tends to invade species-rich but nutrient-poor dry and semi-dry environments, that are home to many rare species assemblages (Kleinbauer et al, 2010). Outside its native range in North America, its rapid growth allows it to compete with otherwise dominant, shade-tolerant species like maple (Acer spp.), ash (Fraxinus spp.), and American beech (Fagus grandifolia Ehrh.) (Hirschfeld et al, 1983). Black locust stands tend to be dense, shading out much of the vegetation growing beneath it and, where dominant, can result in little to no undergrowth (Rahmonov, 2009; Nasir et al, 2005). Phytotoxins have been found in the leaves and other allelochemicals in all parts of the black locust tree, which may play a role in invasion success and explain the apparent lack of plant growth underneath the canopy (Nasir et al, 2005).

Management of natural ecosystems has been challenging for land managers of pine barren, sand prairie, and black oak savanna communities; all examples of specialized communities that were unable to compete with spreading black locust from nearby plantations (Stone, 2009). Spreading black locust has resulted in aggressive removal efforts by land managers where the tree can be particularly invasive (Sleeping Bear Dunes National Lakeshore, 2007; Rice, et al, 2002). Climate change model projections have shown that there is increased risk of the spread of black locust if the temperature continues to rise (Kleinbauer et al, 2010). This may push not only black 
locust, but other invasive species to spread into reserves and habitats with high conservation value around the world.

\section{Gaps in our knowledge}

Several studies have been conducted that look at the effects of black locust on soil and plant communities (Sitzia et al, 2012; Castro-Diez et al, 2009; Motta et al, 2009; Malcom et al, 2008; Von Holle et al, 2006; Nasir et al, 2005; Rice et al, 2002; Peloquin and Hiebert, 1999; Dzwonko and Loster, 1997; Hirschfeld et al, 1983; Chapman, 1935). Soil-based research has looked at not only the addition of nitrogen to the soil system, but also changes in pH, organic content, and rate of weathering (Motta et al, 2009; Von Holle et al, 2006; Rice et al, 2002; Peloquin and Hiebert, 1999; Hirschfeld et al, 1983). Forest plant community studies in relation to black locust trees are relatively rare, mostly looking at other tree associations, and have focused on high light environments and nutrient limited plant groups (Von Holle et al, 2006; Rice et al, 2002; Peloquin and Hiebert, 1999; Dzwonko and Loster, 1997). Few of these studies have taken place within temperate northern hardwood forests established on sandy soils. By characterizing the changes caused by black locust monocultures we can provide information that would facilitate the land managers' decision making process and help determine if black locust removal in forested areas should be a priority.

The forests of north-western lower Michigan, more specifically Sleeping Bear Dunes National Lakeshore (SLBE), features sand-based soils, but the vegetation of the 
mesic hardwood forest is adjusted to dense canopy conditions and deep shade.

Understory plant communities within SLBE can be extremely varied and dependent on soil moisture conditions and the dominant tree species (Hazlett, 1986). Within the last ten years, SLBE has started a black locust removal program, aimed at removing errant invasive trees from the landscape, following observations of a high co-occurrence with the non-native honeysuckle (Lonicera japonica Thunb.) (Mechenich et al, 2009), although this relationship has not been investigated at SLBE. Plantings of black locust have been reported to be invading the beech-maple hardwood forests and sprouting in historic farm fields at SLBE (Sleeping Bear Dunes National Lakeshore, 2007). Initial management efforts began on the dune-forest landscape and have since moved inland to the fields and hardwood forests at SLBE. As all vegetation communities play a significant role in the structure and function of forest ecosystems of the area, determining if black locust is indeed affecting the hardwood forest environment at Sleeping Bear Dunes needs investigation.

The objectives of this study were to 1 ) investigate whether black locust is affecting native understory vegetation richness and diversity by facilitating the invasion of other non-native species, and 2) determine if there are any changes to soil characteristics when compared to a nearby native hardwood stands that might be contributing to a change in vegetation structure. We hypothesized that the black locust monocultures are reducing native understory richness and diversity and are changing the soil characteristics where they are growing. We predict that there will be lower 
overall species richness and diversity with fewer spring ephemerals in the black locust stands compared with native hardwood stands. We also expect higher levels of nitrogen in the soils and less organic matter in the black locust stands since black locust leaf litter has a lower carbon:nitrogen ratio than Acer saccharum Marshall or F. grandifolia, two dominant species in the hardwood forest.

\section{Methods}

\section{Study Area}

The study took place within the boundaries of Sleeping Bear Dunes National Lakeshore (SLBE), which encompasses parts of Leelanau County and Benzie County, Michigan. The landscape at SLBE was strongly influenced by the last glacial period, leaving behind many geographical features that have helped shape the vegetation communities to what they are today (NPS, 2008; Hazlett, 1986). The native forests at SLBE can be classified as mesic northern hardwoods to dry-mesic northern hardwoods (Cohen, 2000), and are typically found on moraines resulting from the last glaciations (NRCS 2012; Haswell and Alanen, 1994; Hazlett, 1986). The northern hardwood forest in this region was strongly influenced by glacial melting, anthropogenic disturbance, and most recently, pests and disease (Hazlett, 1986). A history of logging and agriculture (Appendix I) has resulted in second-growth forests and the removal of much of the pitand-mound micro-topography normally seen in a mesic northern hardwood forest as a 
result of plowing (Flinn and Marks, 2007). As the park was created in 1972, there has not been any active forest management since that time.

Plot locations within SLBE were chosen based on multiple criteria. Management efforts of black locust had already begun so black locust stands that had not yet been managed was the primary selection factor. The decision to focus only on forests of similar composition was influenced by the forests of the Lakeshore itself. The dynamic area contained multiple forest types and ecosystems, with mesic/dry-mesic northern hardwoods being the most common forest type with associated black locust stands. Paired site locations were also chosen based on similarity of the surrounding landscape where flat areas were preferred over small hills or ravines. Fixed-area plots were placed in the approximate center of the black locust stand, determined from shape files provided by the U.S. National Park Service.

This study took place in Leelanau Co., Michigan, in the northern half of SLBE (Figure 2). Paired 0.04 ha forest plots were used to investigate the differences between non-native and native stands, similar to Sitzia et al. (2012). Plot locations were determined by evaluating existing black locust stands and neighboring hardwood forests. Black locust stands were defined as having greater than $50 \%$ live black locust canopy cover. Efforts were taken to ensure that the forest matrix surrounding the black locust was dominated by typical northern hardwood species: $A$. saccharum (sugar maple), Quercus rubra L. (Northern red oak), F. grandifolia (American beech), and Pinus strobus L. (white pine). Both stands of native species and black locust used in the study 
have varying ranges of age and post-disturbance characteristics. Soil maps from NRCS were consulted to ensure that the paired black locust and native hardwood plots had the same soil type. A total of nine individual pairs of black locust/hardwood sites were identified.

Fixed-area plots of 0.04 ha were established in each forest type (nine in the hardwood stands and nine in the black locust, for a total of 18). The plots were established $50 \mathrm{~m}$ from a severe edge to limit edge effects on understory vegetation dynamics. Native fixed-area plots were no more than $300 \mathrm{~m}$ away from the black locust plot and within the same forest matrix that surrounds the black locust stand. Where multiple plot pairs were established within the same black locust stand, a minimum distance of 3 chains $(60 \mathrm{~m})$ was established between the fixed-area plot boundaries. Data collected within the 0.04-ha fixed-area plot included species, diameter, and height of each tree.

Within each 0.04-ha plot, understory vegetation was measured in four, 1- $\mathrm{m}^{2}$ quadrats. The vegetation sub-plots were placed in each cardinal direction, at a randomly selected distance (0.0 to $11.35 \mathrm{~m}$ ) from plot center. Herbaceous cover was estimated with a modified Braun-Blanquet method, with percent cover classes in $5 \%$ intervals (0100), with individuals identified to genus and species where possible (Mueller-Dombois and Ellenburg, 1974). Understory vegetation was measured three times between May 2011 and July 2011. This timing allowed the census of spring ephemerals through latesummer species. Observed cover values for the four vegetation quadrats were averaged 
by sampling time, creating one observed cover value per species per survey time period. The maximum observed cover value for a species was used for statistical analysis to give equal consideration to all species surveyed, regardless of sampling time. This way, species with temporal limitations, including spring ephemerals and late summer species, was still appropriately represented.

At each vegetation sub-plot, percent canopy cover of the overstory was measured using a spherical light densiometer (Forestry Suppliers Inc.). The instrument was held level approximately 30-45 centimeters from the body at elbow height. Measurements were taken by counting the number of quarter squares that were covered by the canopy as reflected in the mirrored surface. This number was multiplied by 1.04, then subtracted from 100 to obtain percent canopy cover (Lemmon, 1956). Measurements were collected in each cardinal direction and over the center of the vegetation sub-plots. This was also repeated at the center of the fixed plot, for a total of 25 measurements. Canopy cover was averaged per vegetation sub-plot, and then averaged across the black locust and hardwood fixed-area plots, respectively.

\section{Soil Sampling and Analysis}

Soil sample cores were taken from the western edge of each vegetation sub-plot with a soil probe $2.5 \mathrm{~cm}$ in diameter. Soil layers were determined by visual color change and consisted of three broad horizons: top, middle and bottom. The top layer was distinguished by a darker color and a higher visual organic matter content. The middle 
layer extended from the top layer to the next zone of color change, which denoted the start of the bottom layer, which was usually the lightest of the three layers (Figure 3). These layers typically represented the classically defined A, B, and C horizons. Horizons were separated and samples from the four vegetation sub-plots were combined by plot location and frozen until such time they could be prepared for analysis.

In the lab, soil was placed in paper bags and dried at $40^{\circ} \mathrm{C}$ for 24 hours in a drying oven. A \#10 sieve was used to remove rocks and large organic matter which also further homogenized each sample. Large soil conglomerates were further reduced by rolling and sieving the samples multiple times until fragments could no longer be reduced.

Samples were processed and then analyzed at the Michigan Technological University Forest Ecology Stable Isotope Laboratory (Houghton, MI, USA). The select soil nutrients ( $\mathrm{C}, \mathrm{N}, \mathrm{K}, \mathrm{Mg}, \mathrm{Ca}, \mathrm{Al})$ were chosen as broad representatives to determine changes in the soil due to time and resource constraints. Soil samples for carbon and nitrogen analysis was finely ground using a Spex mill. This soil was then measured into aluminum tins for analysis; weights of soil varied by soil type and sand/silt composition. Carbon and nitrogen were measured with a Fisons NA 1500 Elemental Analyzer (CE Elantech, Inc., Lakewood, NJ). Exchangeable cation preparation involved placing $5.0 \mathrm{~g}$ of soil into a $125 \mathrm{ml}$ flask and adding $50 \mathrm{ml}$ of $1 \mathrm{M} \mathrm{NH}_{4} \mathrm{OAc}$ (ammonium acetate). Following standard procedures, flasks were then put on a shaker for 2 hours. With a syringe filter, a $15 \mathrm{ml}$ aliquot was placed in a sterile $15 \mathrm{ml}$ centrifuge tube. Blanks of $1 \mathrm{M}$ ammonium acetate were also filtered for testing standards. Potassium, magnesium, calcium, and 
aluminum were assessed at a 1:5 ml dilution using a Perkin Elmer Optima 7000DV ICPOES (PerkinEImer Health Sciences, Inc., Shelton, CT).

\section{Data Analysis}

All vegetation layers were tested for differences in richness, Shannon's diversity index, and evenness between black locust and native hardwood sites. Species diversity (Shannon's) was determined using PAST (Hammer and Harper, 2012),

$H=-\Sigma p_{i} / p_{t} * \ln \left(p_{i} / p_{t}\right)$

where $H$ is Shannon's Index of Diversity, $p_{i}$ is the percent cover of species $i$, and $p_{t}$ is the total species richness for all species in the plot. Evenness was also determined using the PAST program,

$E_{H}=H / H_{\max } \quad H_{\max }=H / \ln (S)$

where $E_{H}$ is evenness, $H_{\max }$ is the maximum potential evenness, and $\ln (S)$ is the natural log of species richness.

Overstory species diversity and evenness was calculated using stem counts in each fixed-area plot. Understory species diversity and evenness was calculated from the maximum observed cover across all sampling periods.

Student's paired t-tests were used to evaluate the differences between black locust and northern hardwood sites, when data was distributed normally. For non- 
normal data, the Wilcoxon's matched-pairs test was performed. Normalcy was tested with the Shapiro-Wilk test (Shapiro and Wilk, 1965) where non-normality is indicated with a $p$-value $<0.05$. Statistical tests were conducted with the statistical program $R$ ( $R$ Core Team, 2012).

\section{Results}

\section{Vegetation Composition}

The total number of understory plant species observed was 54,41 species in black locust stands and 29 in native hardwood stands (Table 1). Of these species, 10 were introduced or considered an exotic or invasive to Northern Michigan. Six of the nine black locust plot contained at least one exotic species, whereas only one of the nine native hardwood plots had an exotic species (Table 1).

Prunus spp. were found in all of the fixed-area plots (18 of 18 plots). Seedlings of A. saccharum and Fraxinus spp. were commonly found as well (17 of 18 plots). $R$. pseudoacacia regeneration was only found in vegetation sub-plots at two locations, Miller Hill C and 677S (Table 2). R. pseudoacacia sprouts were occasionally seen in the black locust fixed-area plots, although seldom fell within the sampled vegetation quadrats. Most of the woody tree species found in the understory vegetation sub-plots appeared to have sprouted within the last year before sampling.

There were no differences found between any of the black locust and native hardwood richness values (Figure 4). Total understory species richness average was 
$10.44( \pm 1.96)$ species in the black locust stands and $9.00( \pm 1.00)$ species in the native hardwood stands, resulting in a p-value $=0.5291$. Herbaceous richness and woody richness comparisons between black locust and hardwood stands resulted in p-values of 0.4833 and 0.7458 , respectively (Table 3 ). Total understory species richness and herbaceous species richness were non-normally distributed (Shapiro-Wilk values: total understory richness: black locust $p$-value $=0.0291$, hardwood $p$-value $=0.4341$; herbaceous understory richness: black locust $p$-value $=0.0184$, hardwood $p$-value $=$ 0.2172). For these comparisons, the paired Wilcoxon signed rank test was used in place of Student's paired t-test.

Shannon’s diversity index for overstory forest composition was $1.07( \pm 0.12)$ for the black locust stands and $0.92( \pm 0.09)$ for the native hardwoods, which was not significantly different $(p$-value $=0.3255)$. Woody species diversity in the understory was $1.11( \pm 0.11)$ in the black locust stand and $1.22( \pm 0.13)$ in the native hardwoods, which was also not significantly different ( $p$-value $=0.4513$, Table 3 ). Diversity values for herbaceous and total understory between black locust and native hardwood stands were not significantly different (Table 3 ).

Evenness for total understory vegetation was similar with $0.64( \pm 0.04)$ and 0.63 $( \pm 0.04)$ in the black locust and hardwood stands, respectively ( $p$-value $=0.9495)$. Further separated into vegetation components of herbaceous and woody species, there was no difference in evenness between black locust and native hardwood stands for the 
understory (Table 3 ). Canopy species evenness was also not significantly different ( $p$ value $=0.5324)$.

\section{Canopy}

Thirteen tree species were observed in the overstory (nine species in black locust stands and 10 in native hardwood stands) (Table 4). Common species between the two stands included: A. saccharum, F. grandifolia, Fraxinus spp., P. strobus, Prunus serotina Ehrh., and Q. rubra. Species observed only in black locust plots were: Malus spp., Prunus pensylvanica, and R. pseudoacacia. Betula papyrifera Marshall, Ostrya virginiana (Mill.) K. Koch, Populus grandidentata Michx., and Tilia americana L. were only found in the native hardwood fixed area plots.

Basal area between the paired plots was significantly different $(p$-value $=0.0147$, Table 5) with the black locust stands having greater overall average basal area (44.26 \pm $\left.5.08 \mathrm{~m}^{2} \mathrm{ha}^{-1}\right)$ per hectare than the native hardwood stand $\left(28.78 \pm 2.38 \mathrm{~m}^{2} \mathrm{ha}^{-1}\right.$ ) (Table 5). Tree counts per hectare were not statistically different with the black locust stands averaging $1247.2( \pm 108.29)$ stems per hectare and native hardwood stands averaging $969.44( \pm 141.28)$ stems per hectare. The quadratic mean diameter (QMD) was not normally distributed, but was similar between the stands. Black locust QMD was 21.5 $\mathrm{cm}( \pm 1.7)$ and $20.5 \mathrm{~cm}( \pm 1.6)$ in the native hardwood stands (Table 5). Tree canopy cover was high for both black locust and native hardwood stands ranging from $98 \%$ to $85 \%$ canopy closure. Differences in the canopy cover between the two stand types were not significant (Table 5). 


\section{Soils}

None of the soil layers from either stand type had significantly different total carbon percentages (Table 6). Total soil carbon percentages ranged from an average of $0.73 \%( \pm 0.08)$ for the lowest soil layer to $5.78 \%( \pm 0.91)$ for the top-most soil layer in the black locust stand, and from $0.68 \%( \pm 0.06)$ in the lowest layer to $4.61 \%( \pm 1.10)$ in the top-most layer in the native hardwood stands (Figure 5).

Total soil nitrogen percentages were not significantly different for any soil layer between the black locust and the native hardwood stands either (Table 6). The top soil layer for the black locust stands averaged $0.39 \%( \pm 0.06)$ nitrogen and the native hardwood stands had a mean of $0.26 \%( \pm 0.06)$ nitrogen. The range of data for both forest stand types was wider for the top-most soil layer than any other soil layer (Figure 6).

The total carbon:nitrogen ratios were significantly different between the two stands in the top and middle soil layers, with the black locust stands having lower $\mathrm{C}: \mathrm{N}$ ratios than the native hardwood stands. Mean C:N ratio in the top soil layer was 14.61 $( \pm 0.28)$ in the black locust stand and $17.61( \pm 1.20)$ in the native hardwood stand $(p-$ value $=0.0293)$. The middle soil layer had a mean of $13.20( \pm 0.89)$ and $17.85( \pm 1.01)$ for the black locust and native hardwood stands, respectively ( $p$-value $=0.0143$ ). The bottom soil layer was not significantly different between the two stand types. 
Potassium concentrations in the soil varied between soil layers (Figure 7). The top soil layer had mean potassium concentrations of $7.49( \pm 0.48) \mathrm{mg} / \mathrm{L}$ in the black locust stands and a mean of $5.81( \pm 0.78) \mathrm{mg} / \mathrm{L}$ in the native hardwood stands, which was not significantly different (Table 6). The middle soil layer and bottom soil layers were not different between the black locust and native hardwood stands, but concentrations of potassium continued to decrease as soil depth increased.

Soil magnesium concentrations showed a great deal of variability across all the soil layers (Figure 8). There was no difference between the black locust and native hardwood stands for the top and bottom soil layers. The native hardwood stands did have a significantly higher mean concentration of magnesium than the black locust stands at $6.76( \pm 3.02) \mathrm{mg} / \mathrm{L}$ in the hardwood stands compared to $3.30( \pm 1.17) \mathrm{mg} / \mathrm{L}$ in the black locust stands ( $p$-value $=0.0391$,Table 6 ).

Calcium concentrations varied with a significant difference in the top soil layer and no differences in the middle and bottom soil layers (Table 6). The black locust stands had, on average, a greater amount of calcium in the top soil layer with 115.34 ( \pm 16.17) $\mathrm{mg} / \mathrm{L}$ compared to that of the native hardwood stands with an average of 73.30 $( \pm 17.16) \mathrm{mg} / \mathrm{L}(\mathrm{p}$-value $=0.0339)$. The hardwood stands averaged $56.31( \pm 32.98) \mathrm{mg} / \mathrm{L}$ of calcium in the mid-soil layer while the black locust stand had a mean of 27.44 ( \pm 11.03) $\mathrm{mg} / \mathrm{L}$ ( $p$-value $=0.0977)$. The bottom soil layer was not significantly different between the stand types (Figure 9). 
Aluminum concentrations in the soil were not significantly different for any of the soil layers between the black locust and native hardwood stands (Figure 10). The top soil layer in black locust stands had $0.61( \pm 0.08) \mathrm{mg} / \mathrm{L}$ and the hardwood stands averaged $0.59( \pm 0.11) \mathrm{mg} / \mathrm{L}(\mathrm{p}$-value $=0.6063)$. Concentrations decreased through the soil profile, with an average of $0.50( \pm 0.07) \mathrm{mg} / \mathrm{L}$ and $0.43( \pm 0.11) \mathrm{mg} / \mathrm{L}$ in the middle and bottom soil layers in the black locust stands. Native hardwood stands averaged 0.46 $( \pm 0.09) \mathrm{mg} / \mathrm{L}$ and $0.37( \pm 0.08) \mathrm{mg} / \mathrm{L}$ in the middle and bottom soil layers (Figure 10).

\section{Discussion}

The objectives of this study were to test for differences between black locust and native hardwood stands by looking at the vegetation structure and soil nutrient profile. Based on literature and previous studies, we hypothesized that black locust would reduce native understory species richness and diversity and alter the soil profile since it is a nitrogen fixer. In the end, we found few differences between measured attributes of these two stand types.

\section{Plant Community Structure}

In this study, black locust did not affect the understory vegetation richness and diversity at Sleeping Bear Dunes National Lakeshore. This is unlike several previous studies that have shown black locust alters species communities, and even facilitates the invasion of other non-native species, particularly into the understory (Von Holle et al, 2006; Rice et al, 2003; Peloquin and Hiebert, 1999; Dzwonko and Loster, 1997). In 
many of these situations, non-natives infiltrated the understory vegetation layer and inhibited the growth of native plants. While $19 \%$ of total herbaceous species were considered exotic or invasive, the low percent cover suggests they are not affecting the growth of native species.

There were no significant differences between black locust dominated stands and native hardwood stands with respect to understory vegetation richness, diversity, or evenness. Similarly, Sitzia et al. (2012) did not find differences between understory richness or diversity between native secondary forest (a Mediterranean Mountain environmental zone, similar to the mesic northern hardwood forest in Michigan) and black locust stands in the foothills of the Eastern Alps, a similar latitude $\left(\sim 45^{\circ} \mathrm{N}\right)$ as the current study. The present study and the study conducted by Sitzia et al. (2012) focused on secondary (previously managed) deciduous temperate forest communities. The other paired studies comparing black locust dominated stands and a native forest type have focused predominantly on pine, pine-oak, or oak-savanna systems (Von Holle et al, 2006; Peloquin and Hiebert, 1999; Dzwonko and Loster, 1997), which typically occur in dryer climates, with less nutrient availability than most temperate hardwood forests. This difference in environmental attributes may help explain why our study showed different results.

Of the 54 understory species observed in this study, ten were non-native and invasive to the northern Michigan region. All non-native or invasive species were found in black locust stands, with the exception of Convallaria majalis L. (European lily-of-the- 
valley), which was found in one native hardwood location, 677 North. The other exotic invasives included Hesperis matronalis L. (dames rocket), Lonicera $x$ bella Zabel (showy fly honeysuckle), Plantago major L. (common plantain), Plantago virginica L. (Virginia plantain), Robinia pseudoacacia (black locust), Rosa multiflora Thunb. (multiflora rose), Rumex acetosella L. (common sheep sorrel), Taraxacum officinale F.H. Wigg. (common dandelion), and Trifolium spp (clover). With the exception of $C$. majalis, these species all display a preference for full to partial sunlight and the ability to quickly colonize disturbed areas (Invasive Plant Atlas of the United States, 2012). Some native species, specifically Galium aparine L. (stickywilly bedstraw), Parthenocissus quinquefolia (L.) Planch. (Virginia creeper), and Toxicodendron radicans (L.) Kuntze (poison ivy) are considered local pests to humans and can achieve invasive levels, although none of the sampled areas were over-run with these species. The higher presence of non-native species in black locust stands could be the result of prior disturbances and land-use history, with these species perpetuated by the greater availability of light later in the season in the black locust stands after the native hardwood canopy has already closed (Figure 11). While exotics account for a high percentage of species (18.52\%), it is merely a count of species presence and does not accurately represent cover or level of establishment. Exotic species found within the vegetation sub-plots averaged a maximum cover value of $5 \%$.

Woody tree seedlings were the most commonly observed individuals in understory plots, with $A$. saccharum, Fraxinus spp., Prunus spp., and $O$. virginiana the 
most common species and often having the largest percent cover. These species are commonly found in mesic northern forest understories, being well adapted to the moist spring leaf litter layers and not requiring a bare mineral soil to germinate (Burns and Honkala, 1990). R. pseudoacacia seedlings were occasionally seen in the black locust stands and beyond the boundaries of black locust dominated areas where canopy cover was less dense.

The overstory diversity in the native hardwood stands, while not different from the diversity of the black locust stands, was lower than the diversity of the understory woody species. The implications of having greater species variety in the understory may be a more diverse overstory in the future. Over time, seedlings in the understory may be able to take advantage of single tree deaths or localized disturbance and grow enough to claim a spot in the canopy. Many of the tree seedlings appeared to have sprouted within the most previous year before sampling, and with the dense canopy, few are expected to make it to the sapling stage. The herbaceous vegetation composition that was present in the native hardwood stands was typical of the mesic northern hardwood forest community. The native herbaceous species assemblages in the black locust dominated stands were also indicative of a mesic northern hardwood community, albeit sparsely represented.

These vegetation results are different than other paired studies of black locust and native forest stands. Von Holle et al (2006), Rice et al (2003), and Peloquin and Hiebert (1999) all studied forests with low canopy cover and xeric plant communities 
where plants are adapted to nutrient-poor soils. In this case, the mesic hardwood forest communities of Northern Michigan are not limited by lack of nutrients, but rather, are stratified by their shade tolerance. In the Von Holle et al. (2006) study at Cape Cod National Seashore, changes in the vertical forest structure may have led to greater invasion pressure in locust stands as more wildlife become attracted to a mid-level shrub layer, increasing the dispersal of non-native seeds into the stand. The lack of the mid-shrub layer in the native pine stands meant less dispersal pressure from animals. Neither the black locust stands nor the native forests at Sleeping Bear Dunes National Lakeshore had a well-represented shrub layer, thus the additional dispersal mechanisms for non-native species was not present. The additional barriers to invasive species, namely lack of light and easy seed dispersal, may be inhibiting non-native species from establishing in these forest communities.

Of the tree species that have achieved canopy or sub-canopy status, Malus spp., P. pensylvanica, and R. pseudoacacia were only found in the black locust dominated stands. Malus spp. was found at the Miller Hill C and Narrows B black locust locations, and was most likely planted or was a remnant from settlement in the immediate area. The limited presence of sun-loving $P$. pensylvanica may be a relic of field succession or human disturbance as well. In all of the black locust study sites and even a few native hardwood study sites, evidence of prior settlement and disturbance was evident, exemplified by old foundations, abandoned machinery and tools, fence rows, and driveway scars. Many of the $R$. pseudoacacia with the largest diameters were found in 
close proximity to these old foundations. Diameters of R. pseudoacacia away from foundations appeared to be normally distributed, suggesting an even-aged structure.

Average basal area per hectare for the black locust stands was greater than the native hardwood stands. Since the density (trees per hectare) was not different between forest types, the greater basal area for black locust stands can be attributed to a larger average diameter in the black locust stands. R. pseudoacacia often had the largest diameter within the fixed area plots, which may be attributed to their routinely fast growth (Boring and Swank, 1984). Mesic northern hardwoods are typically comprised of shade tolerant species, which are usually characterized by slow growth in a competitive environment (Cohen, 2000). Tree canopy cover, which was not different between the two stands, was measured in July during the last vegetation measurement. Leaf cover was fully established at this time in the season so the early spring discrepancies between leaf-out were not evident. The similarity in canopy cover likely contributed to the similarity in understory plant richness and diversity.

\section{Soil Nutrients}

Differences and changes in soil nutrient profiles are highly influenced by the tree species growing there (Binkley and Giardina, 1998). Where other studies involving black locust have shown significant differences in soil nitrogen as well as soil carbon (Von Holle et al, 2006; Dzwonko and Loster, 1997; Boring and Swank, 1984; Chapman, 1935), this study found no differences between the two stand types. The lack of difference 
between black locust and hardwood forests was surprising. Black locust trees are known to deposit up to $75-200 \mathrm{~kg}$ of nitrogen per hectare into the soil per year in their native region (Brady and Well, 2008; Boring and Swank, 1984) and previous studies of black locust outside its native range have shown similar results (Rahmonov, 2009; Rice et al, 2004; Peloquin and Hiebert, 1999). R. pseudoacacia pairs with Rhizobium bacteria to form the nitrogen fixing root nodules; normally Rhizobium is found in the soil when legumes have grown in the area for a sufficient length of time (Brady and Well, 2008). In some cases, when the plant has been grown from seed or stem cuttings, it needs to be inoculated to ensure root nodulation (Brady and Well, 2008; DeGomez and Wagner, 2001) and thus, become nitrogen fixing. Since the black locust trees at SLBE were undoubtedly originally planted by homesteading settlers, it is possible that the original stems were not inoculated with Rhizobium which may have reduced their nitrogen fixing capabilities.

The difference in $\mathrm{C}: \mathrm{N}$ ratio, where black locust had a lower $\mathrm{C}: \mathrm{N}$ ratio in the top and middle soil layers, corresponded with previous studies. Typically this has been attributed to high lignin content in the black locust leaf litter that regulates organic matter accumulation (Boring and Swank, 1984). This distinction is interesting since there were no apparent differences in total carbon and total nitrogen levels between the black locust and native hardwood stands.

There was a greater concentration of calcium in the top most soil layer of the native hardwood stands compared to the black locust stand. This was different from the 
results of pine-deciduous areas from other studies, where the amount of calcium was greater under black locust (Malcom et al, 2008; Von Holle et al, 2006). The propensity for deciduous trees to draw up greater amounts of calcium than coniferous trees (Brady and Well, 2008) may explain why black locust has greater Ca concentration than pinedominated systems of previous studies, and is lower in the deciduous forests that were measured in this study. Greater calcium content could be the result of: 1) greater calcium uptake from deep-rooted tree species such as sugar maple, which dominated many of the hardwood stands (Brady and Wells, 2008), or 2) increased nutrient cycling under N-fixing trees (Binkley and Giardina, 1998), leading to increased leaching potential.

Magnesium concentrations in native hardwood stands had a wider range of abundance than in the black locust stands per soil layer, with the middle soil layer having significantly greater magnesium concentrations in the hardwood stand. The midsoil location of greater quantities of $\mathrm{Mg}$ is most likely due to natural leaching of nutrients to the illuvial layer (Lichter, 1998).

\section{Management Considerations}

In prior studies at both the Ticino Regional Park (Lombardy, Italy), and the Cape Cod National Seashore (Massachusetts, USA), established black locust did not reproduce in any substantial numbers in the absence of disturbance (Motta et al, 2009; Von Holle et al, 2006). In Italy, this resulted in a general reduction in population over several 
decades. In closed canopy forests, small single tree deaths were not enough to initiate a new cohort of black locust, and with time, it is predicted that without human intervention or large disturbances, the forest will return to shade-tolerant, mixed broadleaved species (Motta et al, 2009). This study did not find any appreciable black locust regeneration within the black locust stands at SLBE, or within the forest matrices surrounding the black locust stands. The current threat of the black locust stands expanding into the adjacent forests is low in probability.

Sitzia et al. (2012) found that black locust stands were not altering the typical, native understory species composition differently from native stands. While slight homogenization of understory species abundance in the presence of black locust was noted, they suggest that the "pre-invasion" management goals can be achieved with natural or black locust forest cover. The herbaceous layers of mesic northern hardwoods have been found to have a high degree of resilience when given adequate time to recuperate (Cohen, 2000). With similar understory vegetation species in both black locust and native hardwood stands of the current study, the likelihood of radical vegetation changes caused by the influence of black locust in the overstory seems unlikely. Also, the lack of change to the soil nutrient profile suggests that the nitrogen fixing ability of black locust is not having as great an effect on these soils as in other forest communities. The absence of change in the soil makes it less likely for the plant community outside the black locust stands to be affected, especially without future soil disturbance. 
On nutrient-poor sandy soils, where nitrogen is the limiting resource in the ecosystem, black locust has the ability to alter the plant community by increasing nitrogen availability (Rice et al, 2004; Peloquin and Hiebert, 1999; Dzwonko and Loster, 1997). It is in these ecosystems that black locust can reach its highest potential to disrupt ecosystem structure and function by facilitating invasive species, displacing native species, and changing the soil composition. Likewise, in open and high-light environments, black locust may use the same pathways to accelerate succession, which may disrupt historical successional paths (Stone, 2009). When nitrogen is not a limiting factor and the forest community is composed of intermediate to very shade-tolerant species, the negative effects of black locust appear to be lessened across the landscape.

When managing black locust within a forested landscape it is recommended to let natural vegetation development play its course and let the black locust die out of the forest from natural causes. Restoration efforts have the tendency to be very disruptive and may, in fact, encourage the black locust to reproduce vegetatively due to increased light and its natural response to disturbance. With the minimal differences found in this study, restoration of these forests would cost time and resources that could be focused on other, more substantial threats to the park's natural resources. This is not to say that black locust everywhere at Sleeping Bear Dunes should go unmanaged. Open fields and dune areas may still be at risk for invasion and changes to those environments may be possible. Without the resilient complexities of the forest, these communities are still susceptible to the potential changes black locust can initiate. 


\section{Literature Cited}

Ashby, W.C., and Baker Jr., M.B. 1968. Soil nutrients and tree growth under black locust and shortleaf pine overstories in strip-mine plantings. Journal of Forestry 66(1): 67-71.

Barrett, R.P., Mebrahtu, T., and Hanover, J.W. 1990. Black locust: A multi-purpose tree species for temperate climates. P. 278-283. In: J. Janick and J.E. Simon (eds) Advances in new crops. Timber Press, Portland, OR.

Binkley, D. and Giardina, C. 1998. Why do tree species affect soils? The warp and woof of tree-soil interactions. Biogeochemistry 42: 89-106.

Boring, L.R. and Swank, W.T. 1984. The role of black locust (Robinia pseudoacacia) in forest succession. Journal of Ecology 72(3): 749-766.

Brady, N.C. and Weil, R.R. The nature and properties of soils (fourteenth edition). Prentice Hall Inc. Columbus, Ohio.

Burns, R.M., and Honkala, B.H, tech. coords. 1990. Silvics of North America: 1. Conifers; 2. Hardwoods. Agriculture Handbook 654. U.S. Department of Agriculture, Forest Service, Washington, DC. vol.2, $877 p$

Castro-Diez, P., Gonzalex-Munoz, N., Alonso, A., Gallardo, A. and Pooter, L. 2009. Effects of exotic invasive trees on nitrogen cycling: a case study in Central Spain. Biological Invasions 11: 1973-1986.

Chapman, A.G. 1935. The effects of black locust on associated species with special reference to forest trees. Ecological Monographs 5(1): 37-60.

Cohen, J.G. 2000. Natural community abstract for mesic northern forest. Michigan Natural Features Inventory, Lansing, MI. 9pp.

Cronk, Q.C.B. and Fuller, J.L. 1995. Plant invaders: the threat to natural ecosystems. Chapman and Hall, London.

DAISIE European Invasive Alien Species Gateway, 2008. Robinia pseudoacacia. Available from: http://www.europe-aliens.org/speciesFactsheet.do?speciesld=11942 [Accessed 1st November 2010]. 
DeGomez, T., and Wagner, M.R. 2001. Culture and use of black locust. HortTechnology 11(2): 279-288.

Detwiler, S.B. 1937. The history of shipmast locust. Journal of Forestry 35(8): 709-712.

Dzwonko, Z. and Loster, S. 1997. Effects of dominant trees and anthropogenic disturbances on species richness and floristic composition of secondary communities in southern Poland. Journal of Applied Ecology 34(4): 861-870.

Ehrenfeld, J.G. 2003. Effects of exotic plant invasions on soil nutrient cycling processes. Ecosystems 6(6): 503-523.

Ehrenfeld, J.G., Kourtev, P., and Huang, W. 2001. Changes in soil functions following invasions of exotic understory plants in deciduous forests. Ecological Applications 11(5): 1287-1300.

Flinn, K.M. and Marks, P.L. 2007. Agricultural legacies in forest environments: tree communities, soil properties, and light availability. Ecological Applications 17(2): 452-463.

Hammer, Ø., Harper, D.A.T. and Ryan, P.D. 2001. PAST: Paleotological Statistics software package for education and data analysis. Palaeontologia Electronia 4(1): 9pp.

Haswell, S.O. and Alanen, A.R. 1994. A garden apart: an agricultural and settlement history of Michigan's Sleeping Bear Dunes National Lakeshore region. National Park Service, Midwest Regional Office. 181pp.

Hazlett, B.T. 1986. The terrestrial vegetation and flora of the mainland peninsula of Sleeping Bear Dunes National Lakeshore. University of Michigan Biological Station, Technical Report 13.

Hirschfeld, J.R., Finn, J.T., and Patterson III, W.A. 1983. Effects of Robinia pseudoacacia on leaf litter decomposition and nitrogen mineralization in a northern hardwood stand. Canadian Journal of Forest Research 14: 201-205.

Huntley, J. C. 1990. Robinia pseudoacacia L. black locust. Silvics of North America, Agriculture Handbook 654. U.S. Department of Agriculture, Forest Service, Washington, DC. 2: 755-761. 
Illinois Farmers' Institute. 1914. The eighteenth annual report of the Illinois farmers' institute. Illinois State Journal Co, Springfield, IL. Retrieved from: http://books.google.com/books/about/Annual_report.html?id=wIEOAAAAMAAJ.

Invasive Plant Atlas of the United States. [www.invasiveplantatlas.org]. Accessed: November 13, 2012.

Keresztesi, B. 1988. The black locust. Akadémiai Kiadó. Budapest. 197pp.

Kleinbauer, I., Dullinger, S., Peterseil, J., and Essl, F. 2010. Climate change might drive the invasive tree Robinia pseudoacacia into nature reserves and endangered habitats. Biological Conservation 143: 382-390.

Kroodsma, R.F., 1937. The permanent fixation of sand dunes in Michigan. Journal of Forestry 35(4): 365-371.

Lemmon, P.E. 1956. A spherical densiometer for estimating forest overstory density. Forest Science 2(4): 314-320.

Lichter, J. 1998. Primary succession and forest development on coastal Lake Michigan sand dunes. Ecological Monographs 68(4): 487-510.

Mack, M.C., and D'Antonio, C.M. 1998. Impacts of biological invasions on disturbance regimes. Trends in Ecology and Evolution 13(5): 195-198.

Malcom, G.M., Bush, D.S., and Rice, S.K. 2008. Soil nitrogen conditions approach preinvasion levels following restoration of nitrogen-fixing black locust (Robinia pseudoacacia) stands in a pine-oak ecosystem. Restoration Ecology 16(1): 70-78.

Mechenich, C., Mechenich, D.J., Szczytko, S.W., Cook, J.E., and Kraft G.J. 2009. Assessment of natural resource conditions: Sleeping Bear Dunes National Lakeshore. Natural Resources Report NPS/NRPC/WRD/NRR - 2009/097. National Park Service, Fort Collins, Colorado.

Michener, D.C. 1988. The introduction of black locust (Robinia pseudoacacia L.) to Massachusetts. Arnoldia 48(4).

Motta, R., Nola, P., and Berretti, R. 2009. The rise and fall of the black locust (Robinia pseudoacacia L.) in the "Siro Negri" forest reserve (Lombardy, Italy): lessons learned and future uncertainties. Annals of Forest Science 66(4): 410. 
Mueller, J.M., and Hellmann, J.J. 2008. An assessment of invasion risk from assisted migration. Conservation Biology 22(3): 562-567.

Mueller-Dombois, D. and Ellenburg, H. 1974. Aims and methods of vegetation ecology. Wiley, New York

Nasir, H., Iqbal, Z., Hiradate, S., and Fuji, Y. 2005. Allelopathic potential of Robinia pseudo-acacia L. Journal of Chemical Ecology 31(9): 2179-2192.

National Park Service (NPS) . United States. 2008. Final General Management Plan, Wilderness Study, Environmental Impact Statement. Sleeping Bear Dunes National Lakeshore. [Empire, Michigan] National Park Service.

Natural Resources Conservation Service (NRCS), United States Department of Agriculture. Web Soil Survey. Available online at http://websoilsurvey.nrcs.usda.gov/. Accessed [December 5, 2012].

Peabody, F.J. 1982. A 350-year-old American legume in Paris. Castanea 47(1): 99-104.

Peloquin, R.L., and Hiebert, R.D. 1999. The effects of black locust (Robinia pseudoacacia L.) on species diversity and composition of black oak savanna/woodland communities. Natural Areas Journal 19(2): 121-131.

R Core Team. 2012. R: A language and environment for statistical computing. $R$ Foundation for Statistical Computing, Vienna, Austria. [http://www.Rproject.org/].

Rahmonov, O. 2009. The chemical composition of plant litter of black locust (Robinia pseudoacacia L.) and its ecological role in sandy ecosystems. Acta Ecologia Sinica 29: 237-243.

Rejmánek, M. 1989. Invasibility of plant communities. Biological invasions: a global perspective. John Wiley \& Sons. 369-388.

Rice, S.K., Westerman, B., and Federici, R. 2003. Impacts of the exotic, nitrogen-fixing black locust (Robinia pseudoacacia) on nitrogen-cycling in a pine-oak ecosystem. Plant Ecology 174: 97-107.

Richardson, D.M. 1998. Forestry trees as invasive aliens. Conservation Biology 12(1): 1826. 
Sargent, C.S. 1892. The silva of North America: A description of trees which grow naturally in North America exclusive of Mexico. Houghton Mifflin. Boston, Mass.

Shaprio, S.S., and Wilk, M.B. 1965.An analysis of variance test for normality (complete samples). Biometrika 52:(3/4) 591-611.

Sitzia, T., Campagnaro, T., Dainese, M., Cierjacks, A. 2012. Plant species diversity in alien black locust stands: A paired comparison with native stands across a northMediterranean range expansion. Forest Ecology and Management 285: 85-91.

Sleeping Bear Dunes National Lakeshore. 2007. Removal of invasive black locust trees at Sleeping Bear Dunes, a win-win proposition. [Press Release] Retrieved from: http://www.nps.gov/slbe/parknews/newsremoveblacklocust050107.htm

Stone, K.R. 2009. Robinia pseudoacacia. In: Fire Effects Information System [Online]. U.S. Department of Agriculture, Forest Service, Rocky Mountain Research Station, Fire Sciences Laboratory (Producer). Available: http://www.fs.fed.us.database/feis/.

Sutherland, S. 2004. What makes a weed a weed: life history traits of native and exotic plants in the USA. Oecologia 141: 24-39.

USDA, NRCS. 2013. The PLANTS Database.. National Plant Data Team, Greensboro, NC 27401-4901 USA. [http://plants.usda.gov]. March 5, 2011.

Vitousek, P.M. 1990. Biological invasions and ecosystem processes: towards an integration of population biology and ecosystem studies. Oikos 57: 7-13.

Vitousek, P.M. and Walker, L.R. 1989. Biological invasion by Myrica faya in Hawai'i: Plant demography, nitrogen fixation, ecosystem effects. Ecological Monographs 59(3): 247-265.

Von Holle, B., Joseph, K.A., Largay, E.F. and Lohnes, R.G. 2006. Facilitations between the introduced nitrogen-fixing tree, Robinia pseudoacacia, and nonnative plant species in the glacial outwash upland ecosystem of Cape Cod, MA. Biodiversity and Conservation 15: 2197-2215.

Williamson, M. and Fitter, A. 1996. The varying success of invaders. Ecology 77(6): 16611666. 


\section{Tables}

Table 1: Species richness by plot, broken down by native and exotic species. The proportion of exotic species to the total amount of species is broken down by individual plots, as well as for all species found during the study.

\begin{tabular}{|c|c|c|c|c|}
\hline Plot & $\begin{array}{l}\text { Native } \\
\text { Species }\end{array}$ & $\begin{array}{c}\text { Exotic } \\
\text { Species }\end{array}$ & $\begin{array}{c}\text { Total } \\
\text { Species }\end{array}$ & $\begin{array}{l}\text { Proportion of } \\
\text { Exotic Species }\end{array}$ \\
\hline \multicolumn{5}{|l|}{ Shell Lake } \\
\hline Black Locust & 21 & 3 & 24 & $12.50 \%$ \\
\hline Hardwood & 12 & 0 & 12 & $0.00 \%$ \\
\hline \multicolumn{5}{|l|}{ Hooper Road } \\
\hline Black Locust & 6 & 0 & 6 & $0.00 \%$ \\
\hline Hardwood & 12 & 0 & 12 & $0.00 \%$ \\
\hline \multicolumn{5}{|l|}{ Miller Hill A } \\
\hline Black Locust & 6 & 0 & 6 & $0.00 \%$ \\
\hline Hardwood & 10 & 0 & 10 & $0.00 \%$ \\
\hline \multicolumn{5}{|l|}{ Miller Hill B } \\
\hline Black Locust & 8 & 1 & 9 & $11.11 \%$ \\
\hline Hardwood & 8 & 0 & 8 & $0.00 \%$ \\
\hline \multicolumn{5}{|l|}{ Miller Hill C } \\
\hline Black Locust & 7 & 2 & 9 & $22.22 \%$ \\
\hline Hardwood & 9 & 0 & 9 & $0.00 \%$ \\
\hline \multicolumn{5}{|l|}{ Narrows A } \\
\hline Black Locust & 7 & 4 & 11 & $36.36 \%$ \\
\hline Hardwood & 5 & 0 & 5 & $0.00 \%$ \\
\hline \multicolumn{5}{|l|}{ Narrows B } \\
\hline Black Locust & 12 & 4 & 16 & $25.00 \%$ \\
\hline Hardwood & 5 & 0 & 5 & $0.00 \%$ \\
\hline \multicolumn{5}{|l|}{677 North } \\
\hline Black Locust & 5 & 0 & 5 & $0.00 \%$ \\
\hline Hardwood & 12 & 1 & 13 & $7.69 \%$ \\
\hline \multicolumn{5}{|l|}{677 South } \\
\hline Black Locust & 6 & 2 & 8 & $25.00 \%$ \\
\hline Hardwood & 7 & 0 & 7 & $0.00 \%$ \\
\hline \multicolumn{5}{|l|}{ All Plots } \\
\hline Black Locust & 31 & 10 & 41 & $24.39 \%$ \\
\hline Hardwood & 28 & 1 & 29 & $3.45 \%$ \\
\hline All species & 44 & 10 & 54 & $18.52 \%$ \\
\hline
\end{tabular}




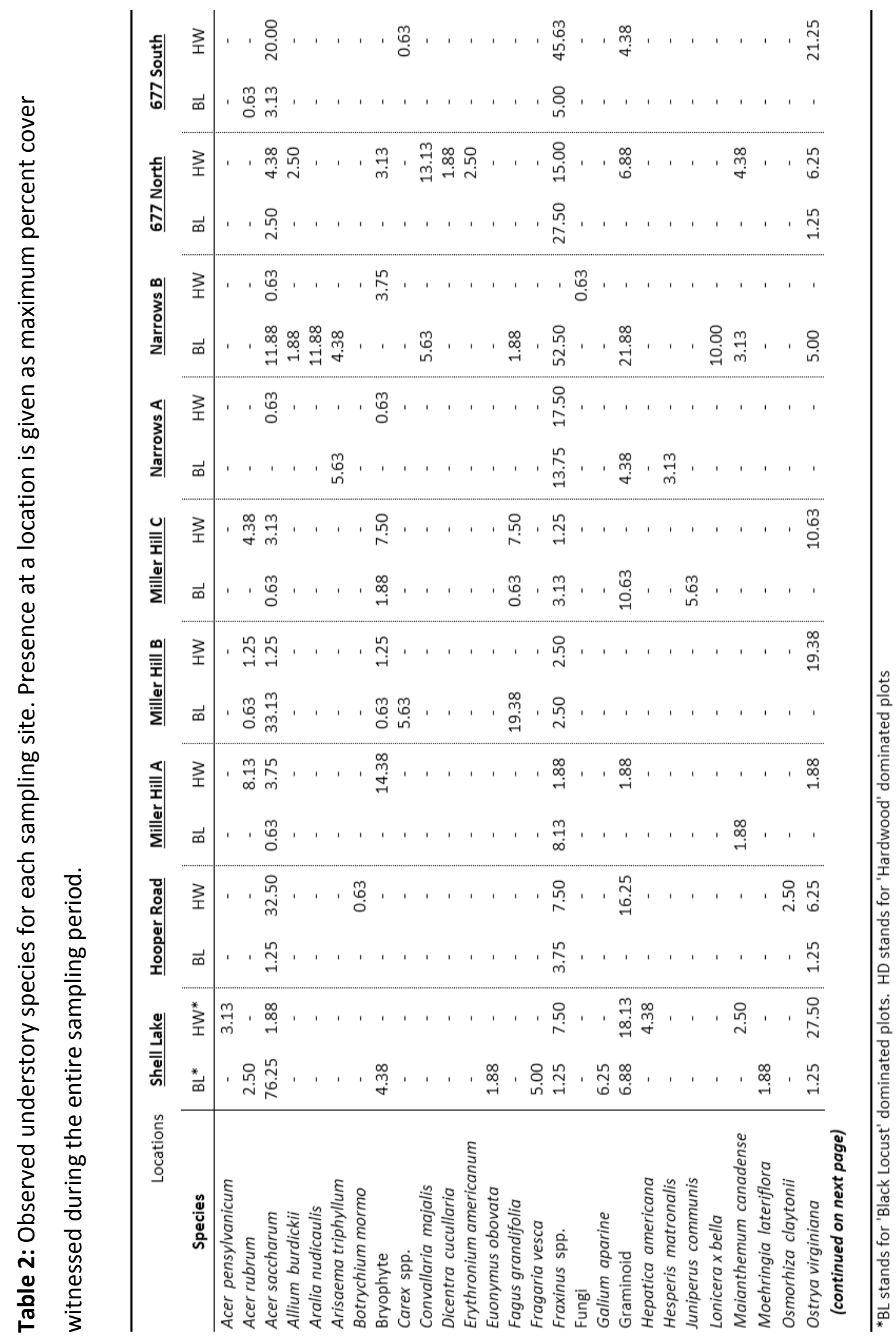




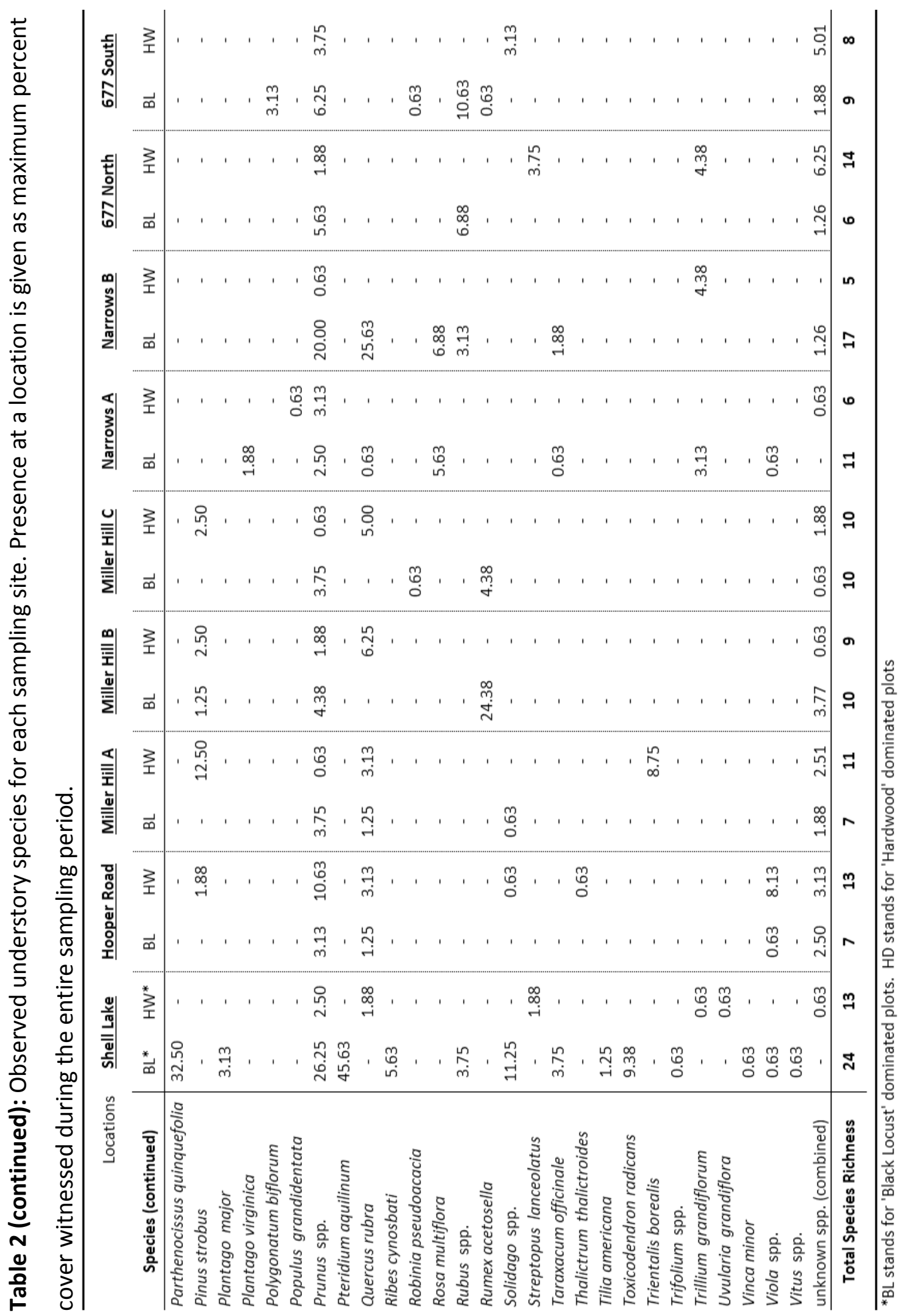


Table 3: Average species richness, Shannon's diversity index, and evenness for all forest vegetation layers ( \pm one SE) for black locust and native hardwood forest stands.

\begin{tabular}{|c|c|c|c|}
\hline & Black Locust & Hardwood & $p$-value \\
\hline \multicolumn{4}{|l|}{ Overstory } \\
\hline Richness & $4.56 \pm 0.38$ & $3.89 \pm 0.35$ & 0.1114 \\
\hline Shannon's Diversity Index & $1.07 \pm 0.12$ & $0.92 \pm 0.09$ & 0.3255 \\
\hline Evenness & $0.67 \pm 0.05$ & $0.73 \pm 0.07$ & 0.5324 \\
\hline \multicolumn{4}{|l|}{ Woody Understory } \\
\hline Richness & $5.00 \pm 0.37$ & $5.22 \pm 0.62$ & 0.7458 \\
\hline Shannon's Diversity Index & $1.11 \pm 0.11$ & $1.22 \pm 0.13$ & 0.4513 \\
\hline Evenness & $0.64 \pm 0.05$ & $0.71 \pm 0.05$ & 0.1822 \\
\hline \multicolumn{4}{|l|}{ Herbaceous Understory } \\
\hline Richness $^{\ddagger}$ & $5.44 \pm 1.83$ & $3.78 \pm 0.92$ & 0.4833 \\
\hline Shannon's Diversity Index & $1.00 \pm 0.28$ & $0.78 \pm 0.23$ & 0.6205 \\
\hline Evenness & $0.78 \pm 0.06$ & $0.80 \pm 0.06$ & 0.8571 \\
\hline \multicolumn{4}{|l|}{ Total Understory } \\
\hline Richness $^{\ddagger}$ & $10.44 \pm 1.96$ & $9.00 \pm 1.00$ & 0.5281 \\
\hline Shannon's Diversity Index & $1.77 \pm 0.13$ & $1.67 \pm 0.16$ & 0.7035 \\
\hline Evenness & $0.64 \pm 0.04$ & $0.63 \pm 0.04$ & 0.9495 \\
\hline
\end{tabular}

$\ddagger_{\text {indicates non-normal distribution }}$ 


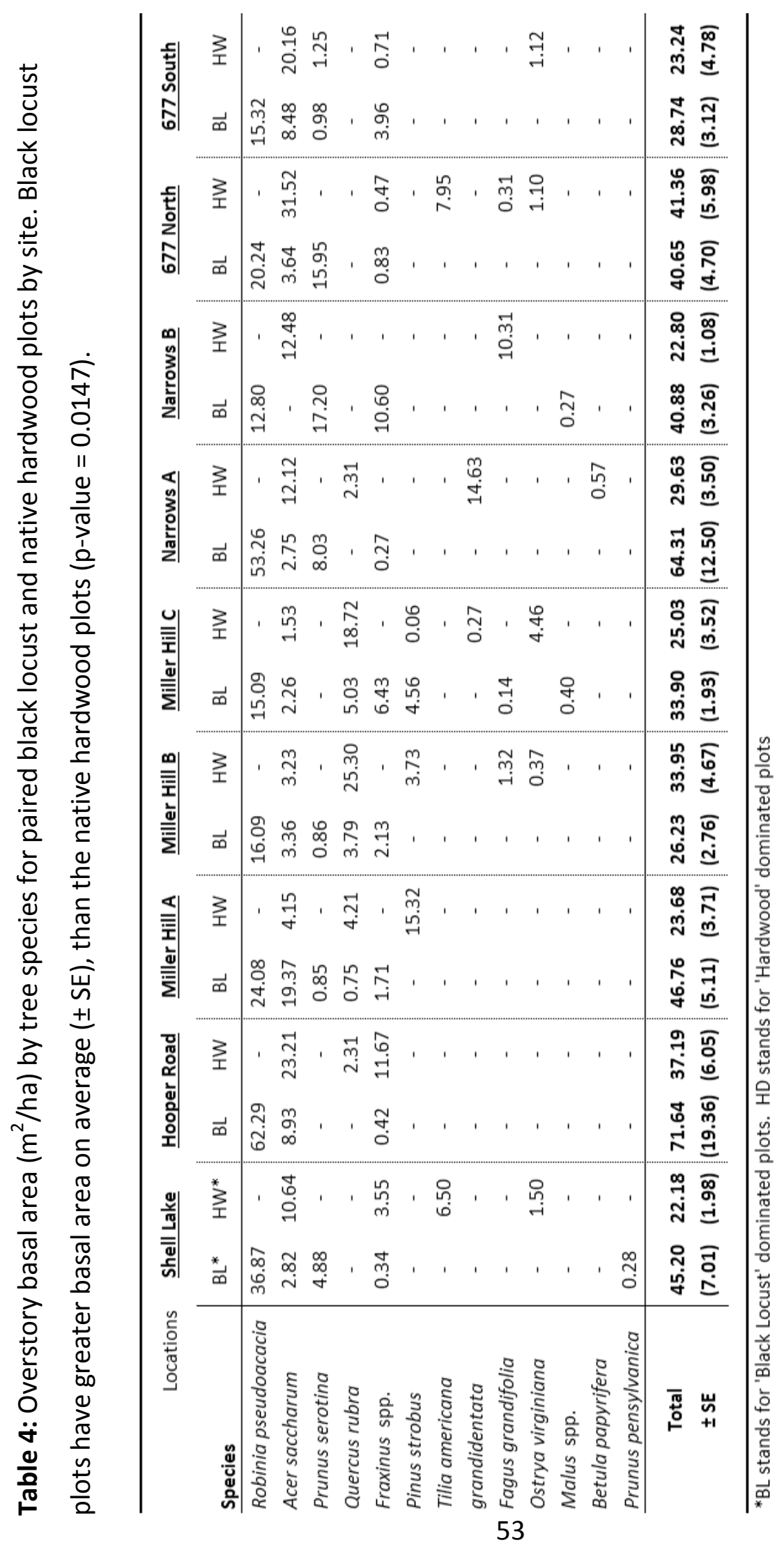


Table 5: A summary of primary vegetation measurements, including average basal area, tree counts, quadratic mean diameter, and percent canopy closure ( \pm one SE) for black locust and native hardwood stands.

\begin{tabular}{|c|c|c|c|c|}
\hline & & Black Locust & Native Hardwood & \\
\hline Measure & Units & Mean & Mean & $p$-value \\
\hline Basal Area & $\left(\mathrm{m}^{2} / \mathrm{ha}\right)$ & $44.26 \pm 5.08$ & $28.78 \pm 2.38$ & 0.0147 \\
\hline Tree Count & (trees/ha) & $1247.22 \pm 108.29$ & $977.22 \pm 146.43$ & 0.2534 \\
\hline Quadratic Mean Diameter & $(\mathrm{cm})$ & $21.47 \pm 1.72$ & $20.54 \pm 1.56$ & 1.0000 \\
\hline Canopy Closure & (\% closed) & $93.60 \pm 1.08$ & $94.16 \pm 1.17$ & 0.5143 \\
\hline
\end{tabular}


Table 6: Results of the soil nutrient analysis. The mean soil nutrient data ( \pm one SE) is presented. $n=$ number of sites used for analysis and bold $p$-values denote significant differences.

\begin{tabular}{|c|c|c|c|c|c|}
\hline Nutrient & $\underline{\text { Soil Layer }}$ & $\underline{n}$ & Black Locust & Hardwood & p-value \\
\hline \multirow[t]{3}{*}{ Organic Carbon (\%) } & Top & 9 & $5.78(0.91)$ & $4.61(1.10)$ & $0.2500^{\ddagger}$ \\
\hline & Middle & 9 & $1.54(0.52)$ & $1.69(0.58)$ & $0.3525^{\ddagger}$ \\
\hline & Bottom & 9 & $0.73(0.08)$ & $0.68(0.06)$ & 0.6608 \\
\hline \multirow[t]{3}{*}{ Total Nitrogen (\%) } & Top & 9 & $0.39(0.06)$ & $0.26(0.06)$ & $0.1289^{\ddagger}$ \\
\hline & Middle & 9 & $0.11(0.04)$ & $0.09(0.03)$ & $0.1069^{\ddagger}$ \\
\hline & Bottom & 9 & $0.05(0.01)$ & $0.04(0.00)$ & 0.2415 \\
\hline \multirow[t]{3}{*}{$\mathrm{C}: \mathrm{N}$} & Top & 9 & $14.61(0.28)$ & $17.61(1.20)$ & 0.0239 \\
\hline & Middle & 9 & $13.20(0.89)$ & $17.85(1.01)$ & $0.0143^{\ddagger}$ \\
\hline & Bottom & 9 & $14.73(0.65)$ & $16.49(1.01)$ & 0.1825 \\
\hline \multirow[t]{3}{*}{ Potassium (mg/L) } & Top & 8 & $7.49(0.48)$ & $5.81(0.78)$ & $0.0781^{\ddagger}$ \\
\hline & Middle & 9 & $2.51(0.28)$ & $3.06(0.56)$ & $0.4258^{\neq}$ \\
\hline & Bottom & 9 & $1.86(0.22)$ & $1.87(0.11)$ & $1.0000^{\ddagger}$ \\
\hline \multirow[t]{3}{*}{ Magnesium (mg/L) } & Top & 8 & $13.32(2.15)$ & $9.85(2.55)$ & $0.2500^{\ddagger}$ \\
\hline & Middle & 9 & $3.30(1.17)$ & $6.76(3.02)$ & $0.0391^{\ddagger}$ \\
\hline & Bottom & 9 & $1.88(0.51)$ & $3.70(1.27)$ & $0.1641^{\ddagger}$ \\
\hline \multirow[t]{3}{*}{ Calcium (mg/L) } & Top & 8 & $115.34(16.17)$ & 73.30 (17.16) & 0.0339 \\
\hline & Middle & 9 & 27.44 (11.03) & $56.31(32.98)$ & $0.0977^{\ddagger}$ \\
\hline & Bottom & 9 & $12.70(3.82)$ & $21.98(7.87)$ & $0.2031^{\ddagger}$ \\
\hline \multirow[t]{3}{*}{ Aluminum (mg/L) } & Top & 8 & $0.61(0.08)$ & $0.59(0.11)$ & 0.6063 \\
\hline & Middle & 9 & $0.50(0.07)$ & $0.46(0.09)$ & 0.6539 \\
\hline & Bottom & 9 & $0.43(0.11)$ & $0.37(0.08)$ & 0.8338 \\
\hline
\end{tabular}


Figures

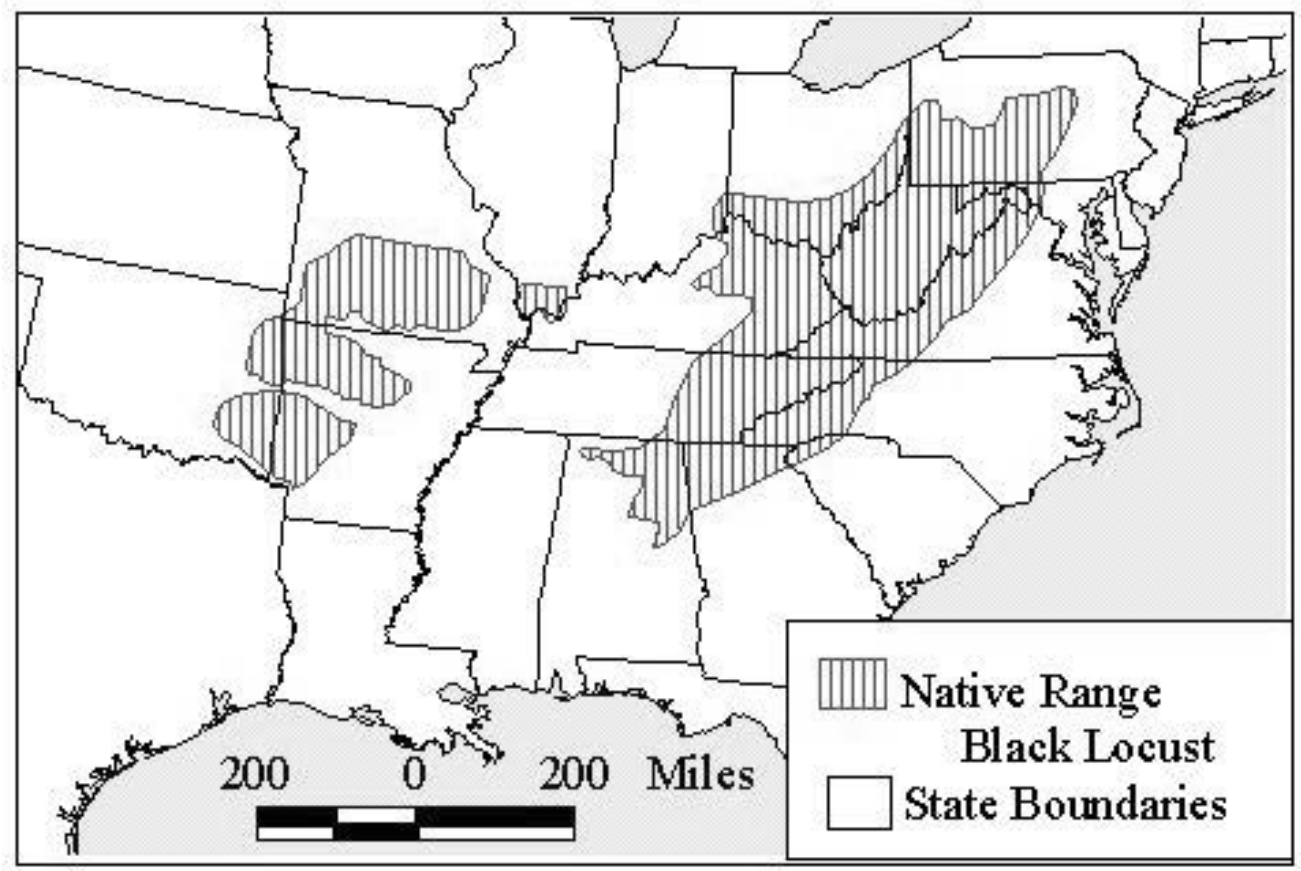

Figure 1: Native range of Robinia pseudoacacia, the black locust tree.

From USDA Forest Service Pest Alert, NA-PR-01-01, Locust leafminer, 2001. 


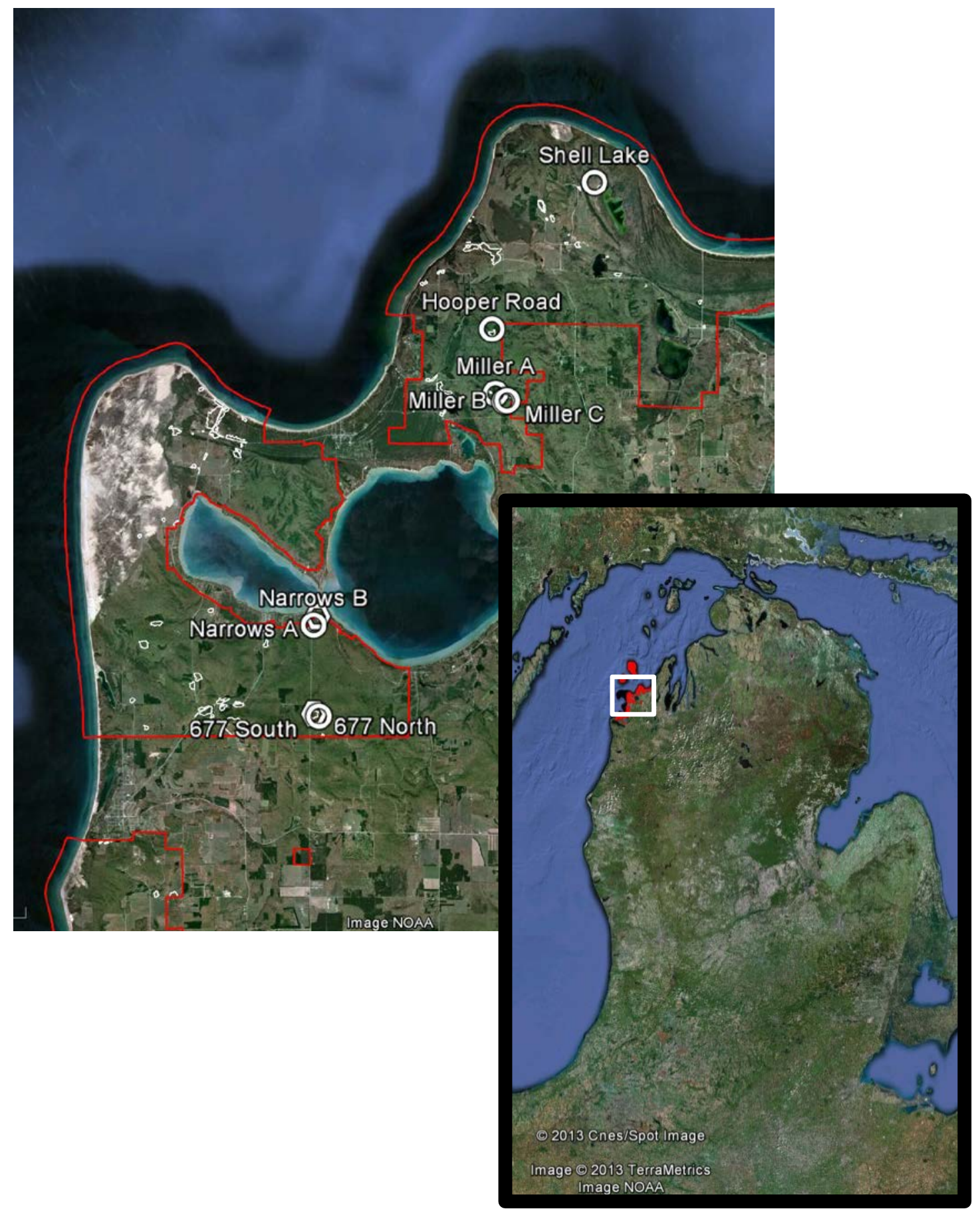

Figure 2: Map of study location, Sleeping Bear Dunes National Lakeshore, Michigan. Maps of individual pair locations can be found in Appendix II. Images (C2013 Google 


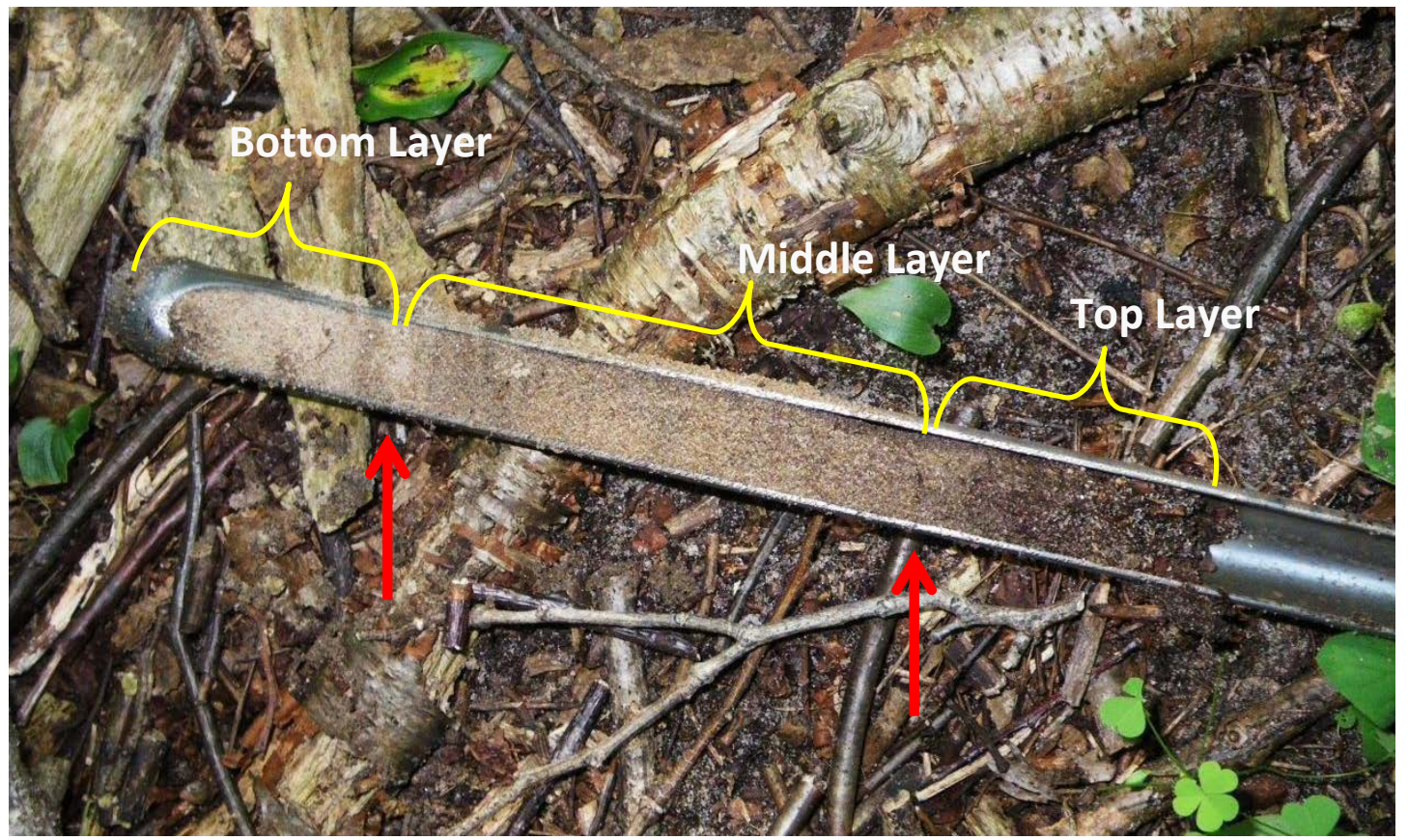

Figure 3: Soil core sample, illustrating visual cues used to separate soil layers (red arrows). Individual layers were separated, placed in separate containers, and frozen until which time analysis could be performed. 


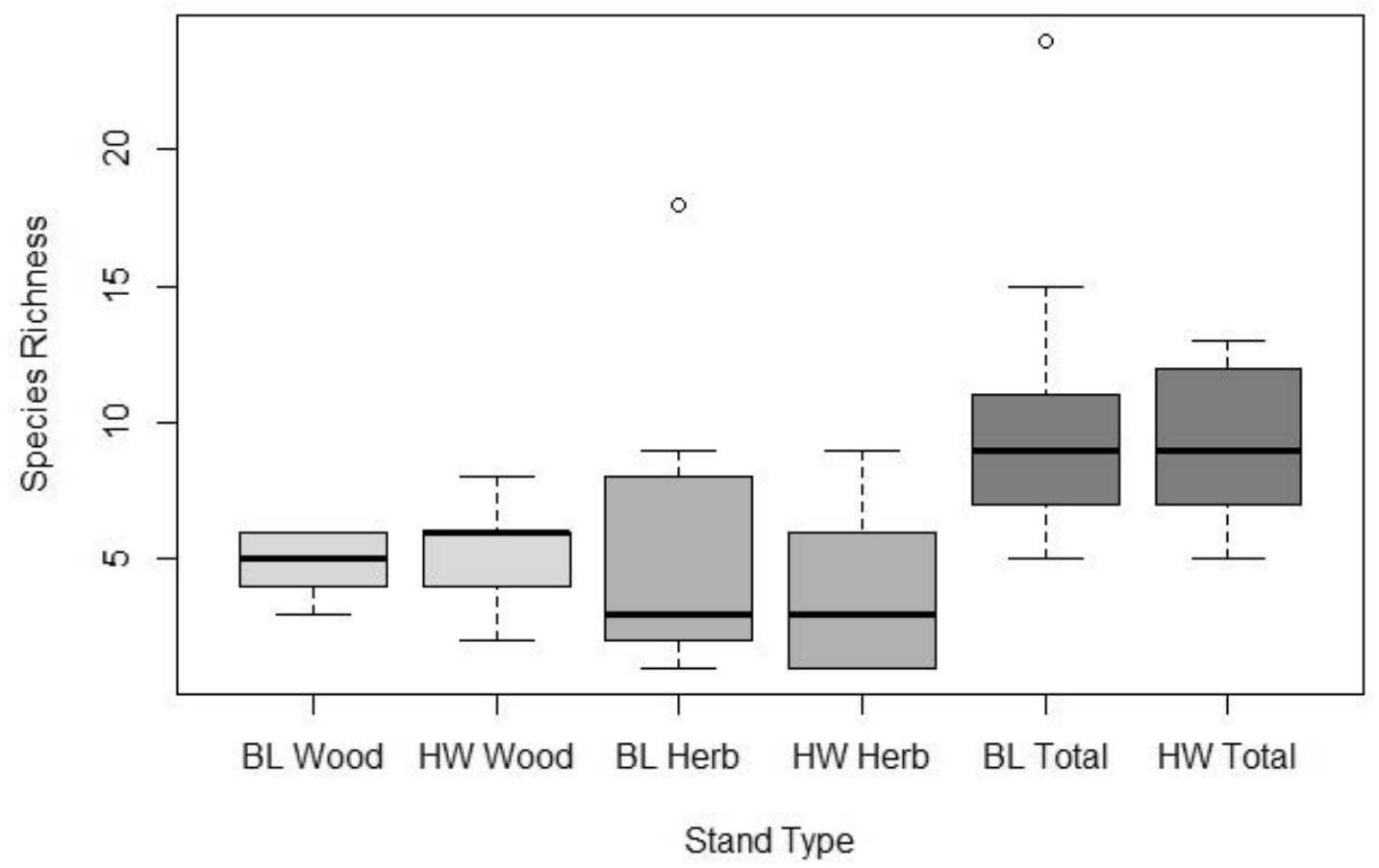

Figure 4: Understory species richness between black locust and native hardwood sample sites, separated by woody tree species, herbaceous species, and total species combined. 'BL' represents black locust stand types and ' $\mathrm{HW}$ ' represents native hardwood stand types (Woody richness: $\mathrm{p}$-value $=0.7458$; Herbaceous richness: Wilcoxon signed rank test, $\mathrm{p}$-value $=0.4833$; Total richness: Wilcoxon signed rank test, $\mathrm{p}$-value $=0.5281)$. The whiskers delineate the range of data, and the box represents the interquartile values (middle 50\%). The bold line shows the median value, and is not necessarily equal to the mean value. Outliers (represented by circles) are beyond the expected range of data (1.5* the interquartile range). All data was tested with a $95 \%$ confidence interval. 


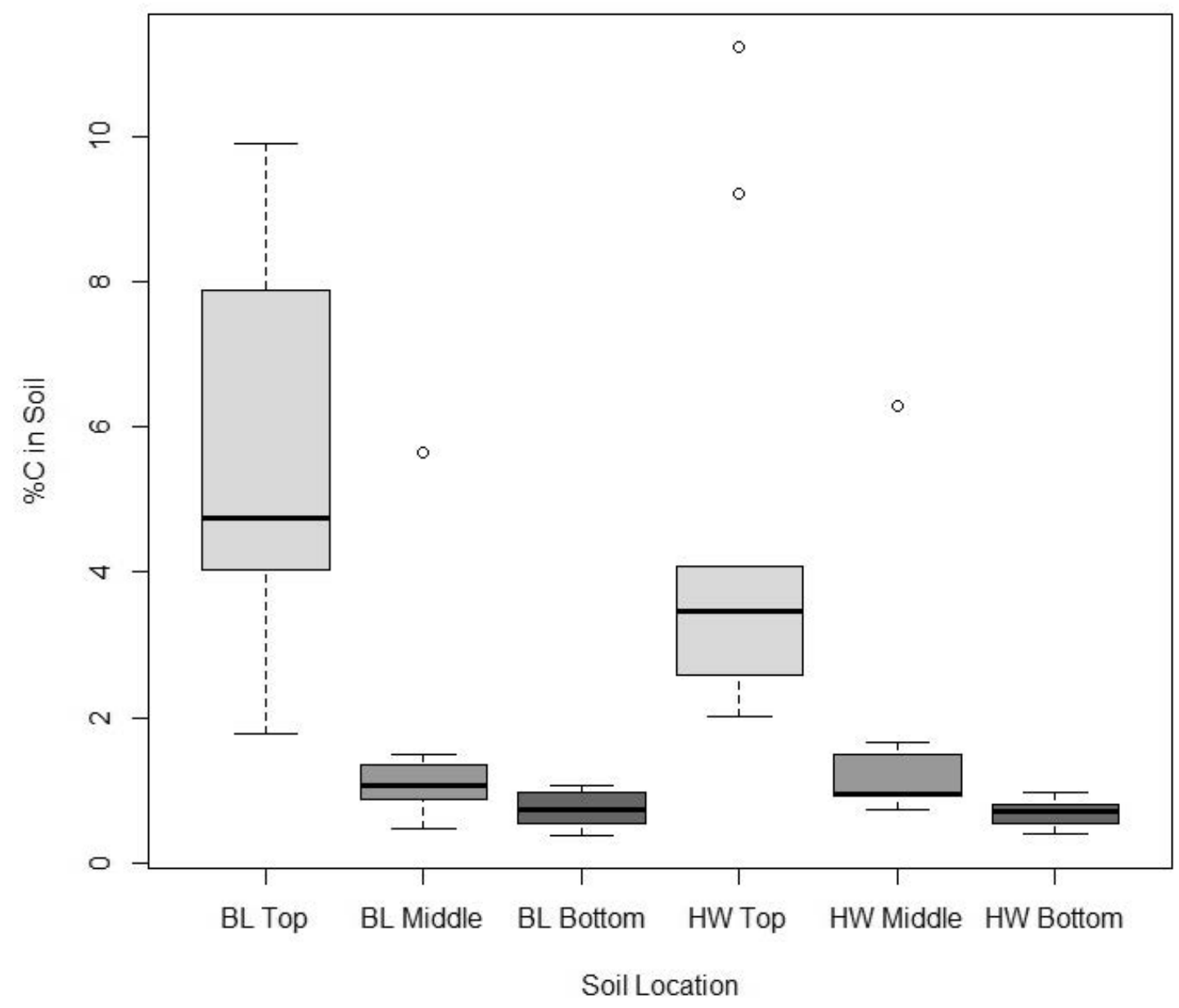

Figure 5: Box and whisker plot for percent organic carbon found in top, middle, and bottom visual soil horizons for black locust (BL) and native hardwood (HW) stands. 


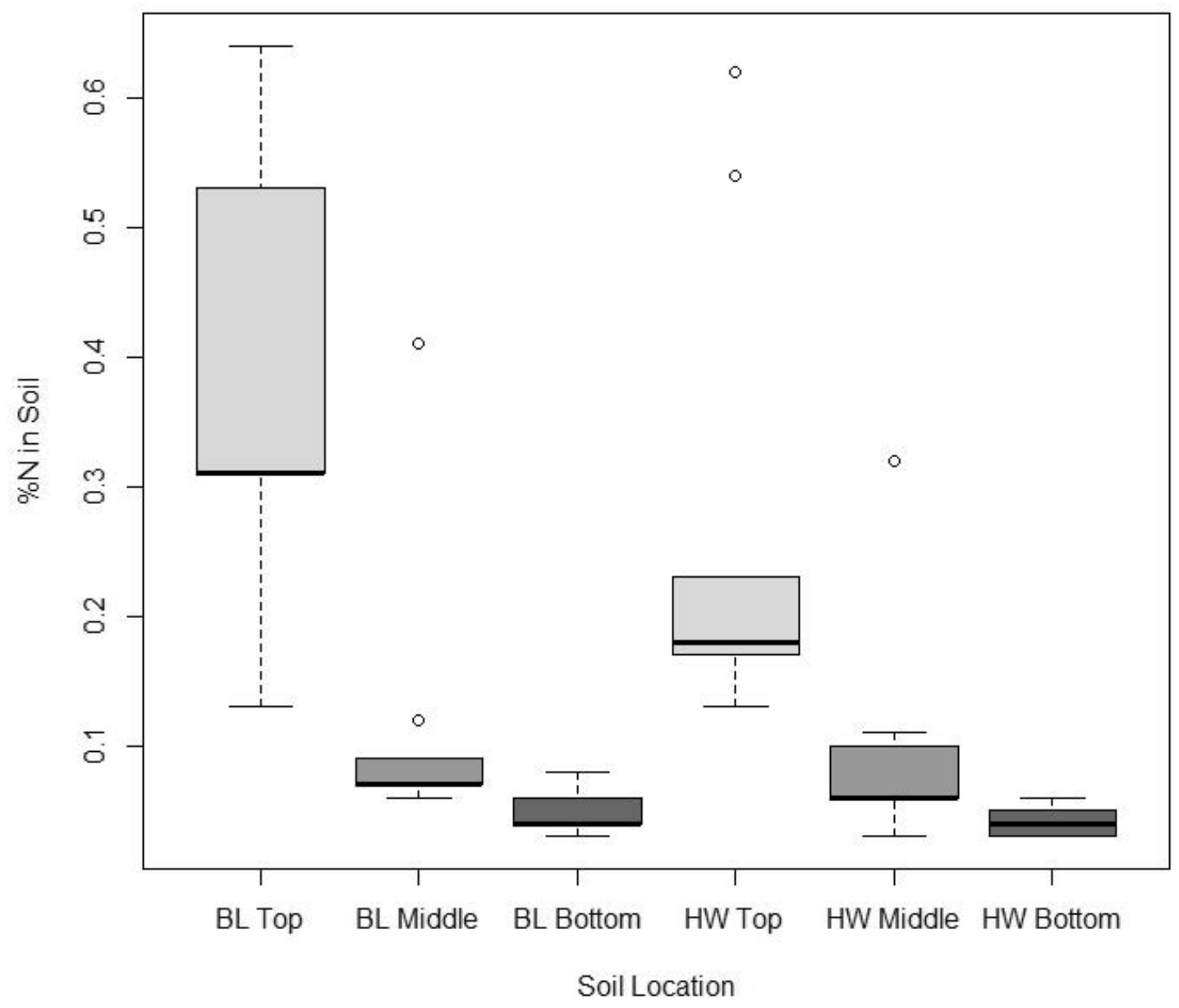

Figure 6: Percent total nitrogen concentrations found in visual soil horizons at black locust (BL) and native hardwood (HW) stands. 


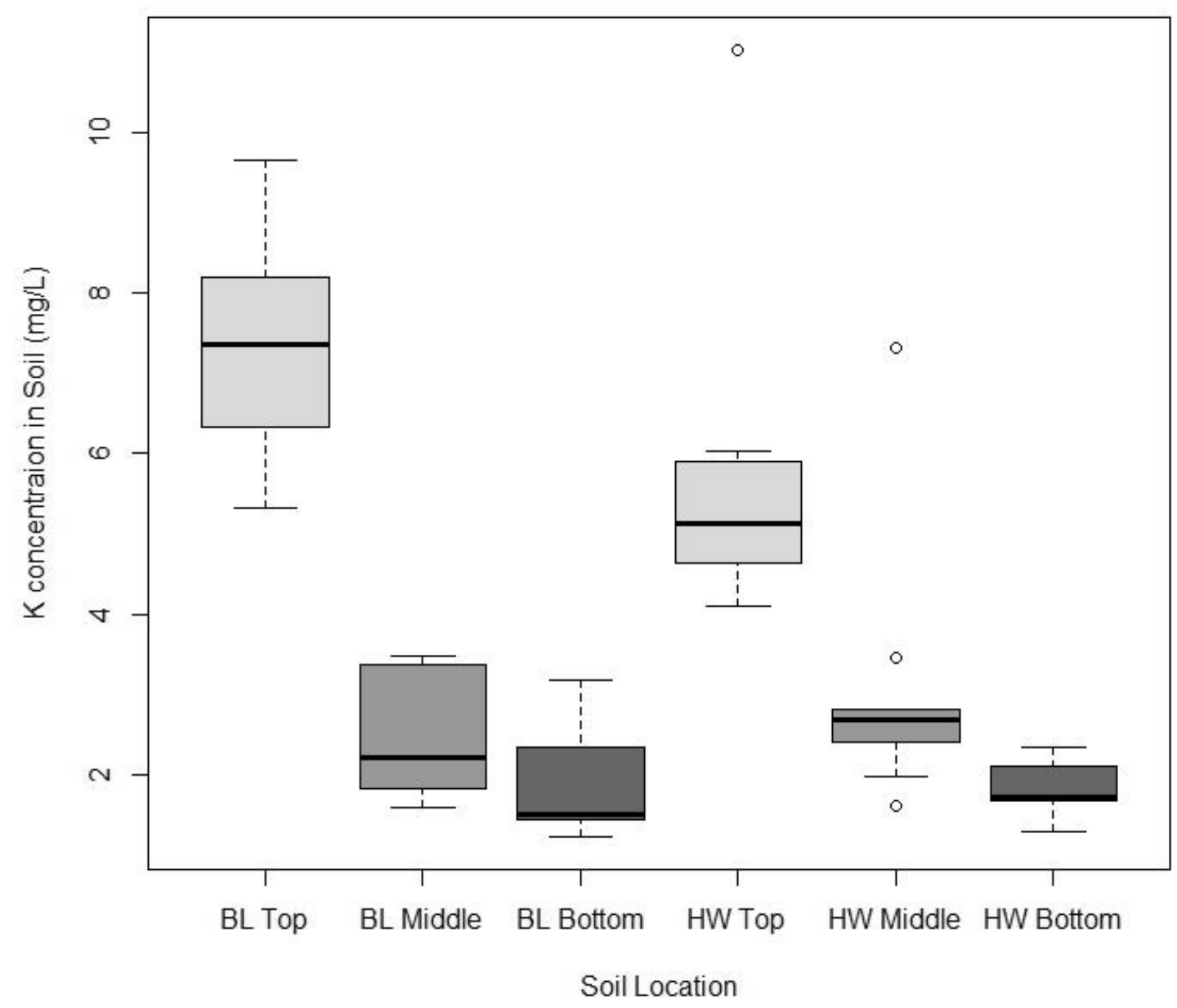

Figure 7: Range of soil potassium concentrations $(\mathrm{mg} / \mathrm{L})$ for soil layers in black locust $(\mathrm{BL})$ and native hardwood (HW) stands. 


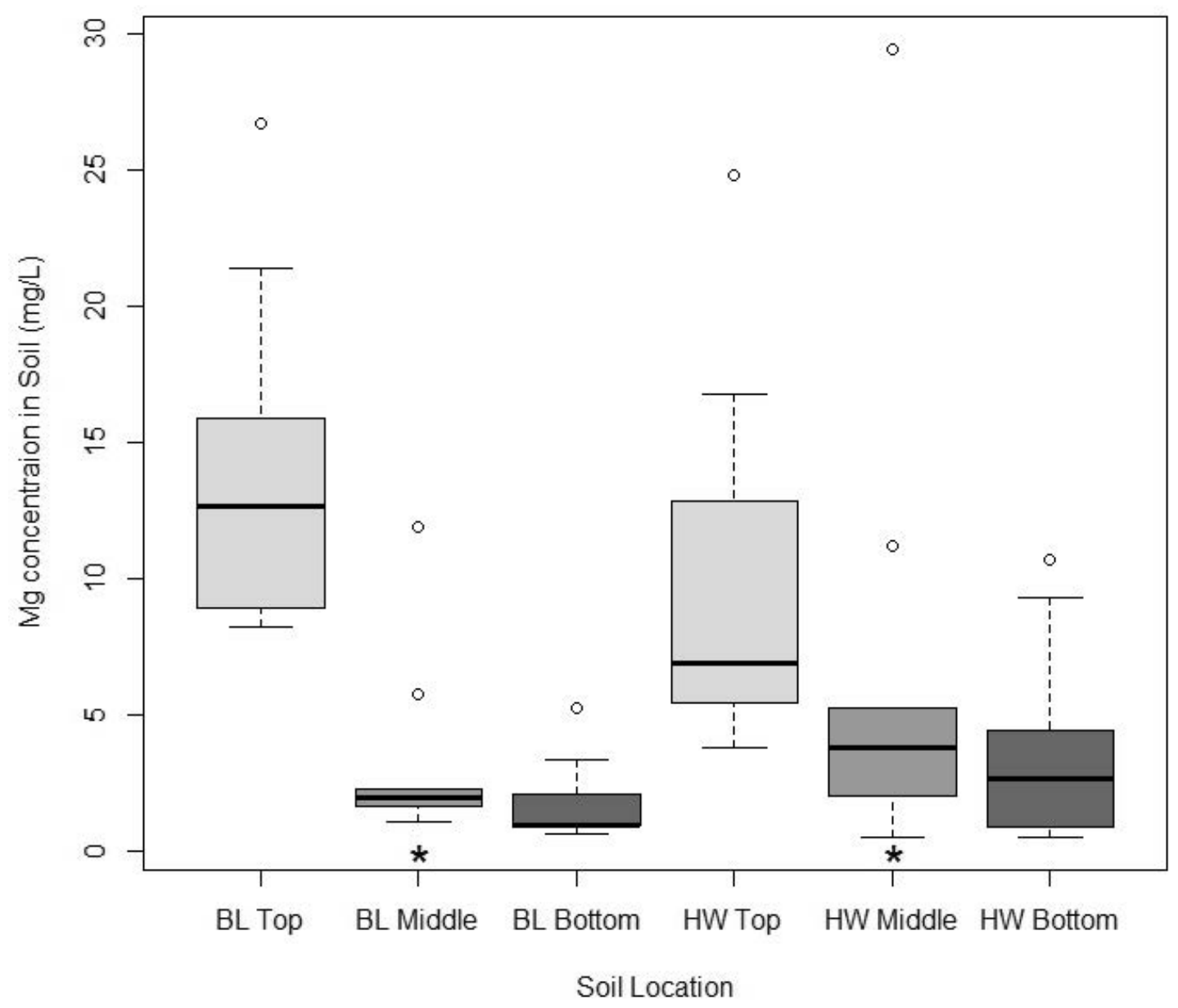

Figure 8: Magnesium concentrations in top, middle, and bottom soil layers in black locust (BL) and native hardwood (HW) dominated stands. The * underneath the box plot indicates statistical significance between the black locust and hardwood middle layers $(p$-value $=0.0391)$. 


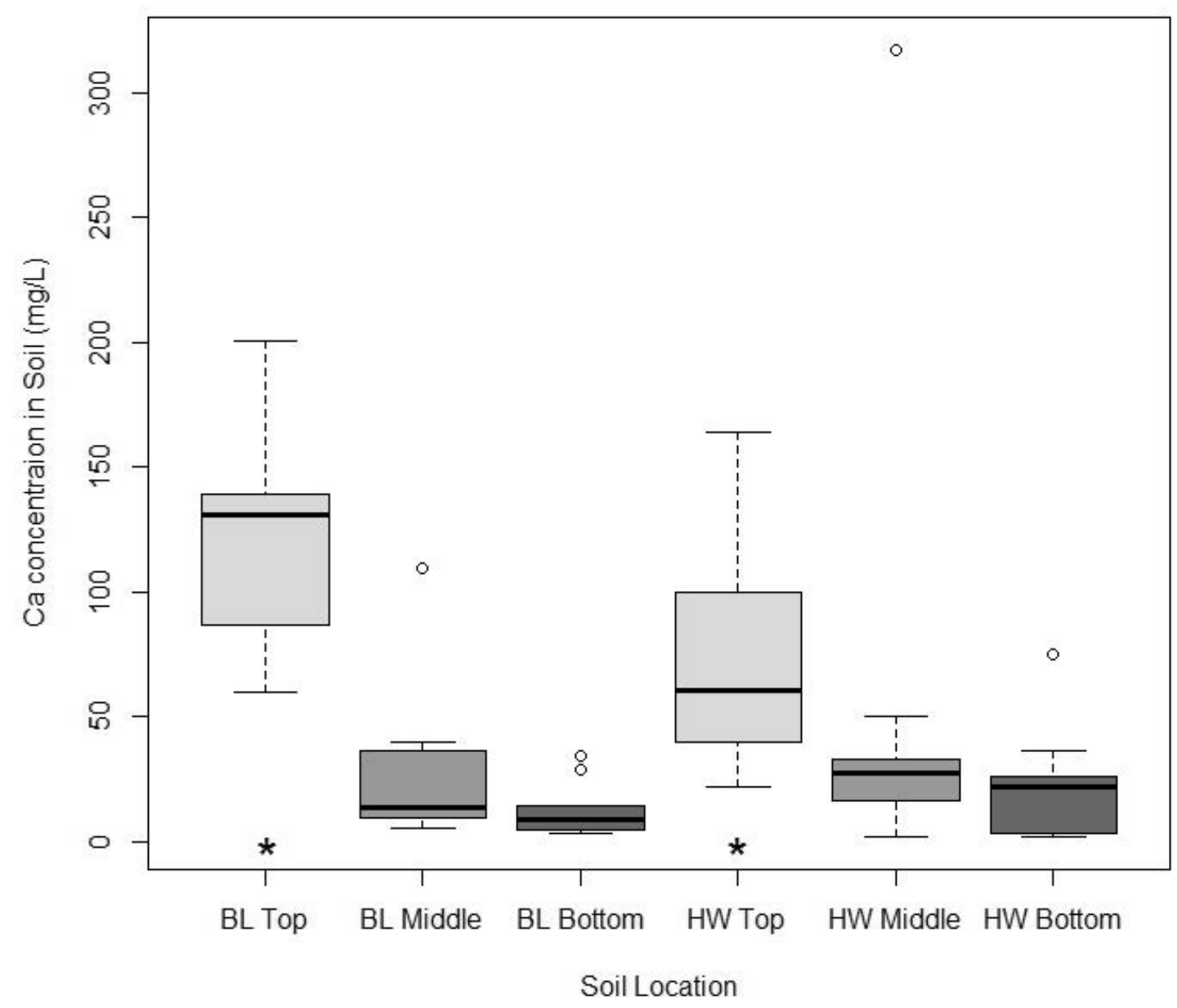

Figure 9: Concentration of calcium in top, middle, and bottom soil layers of the black locust $(\mathrm{BL})$ and native hardwood $(\mathrm{HW})$ stands. The * denotes significant differences between top soil layers in the black locust and hardwood stands ( $p$-value $=0.0339$ ). 


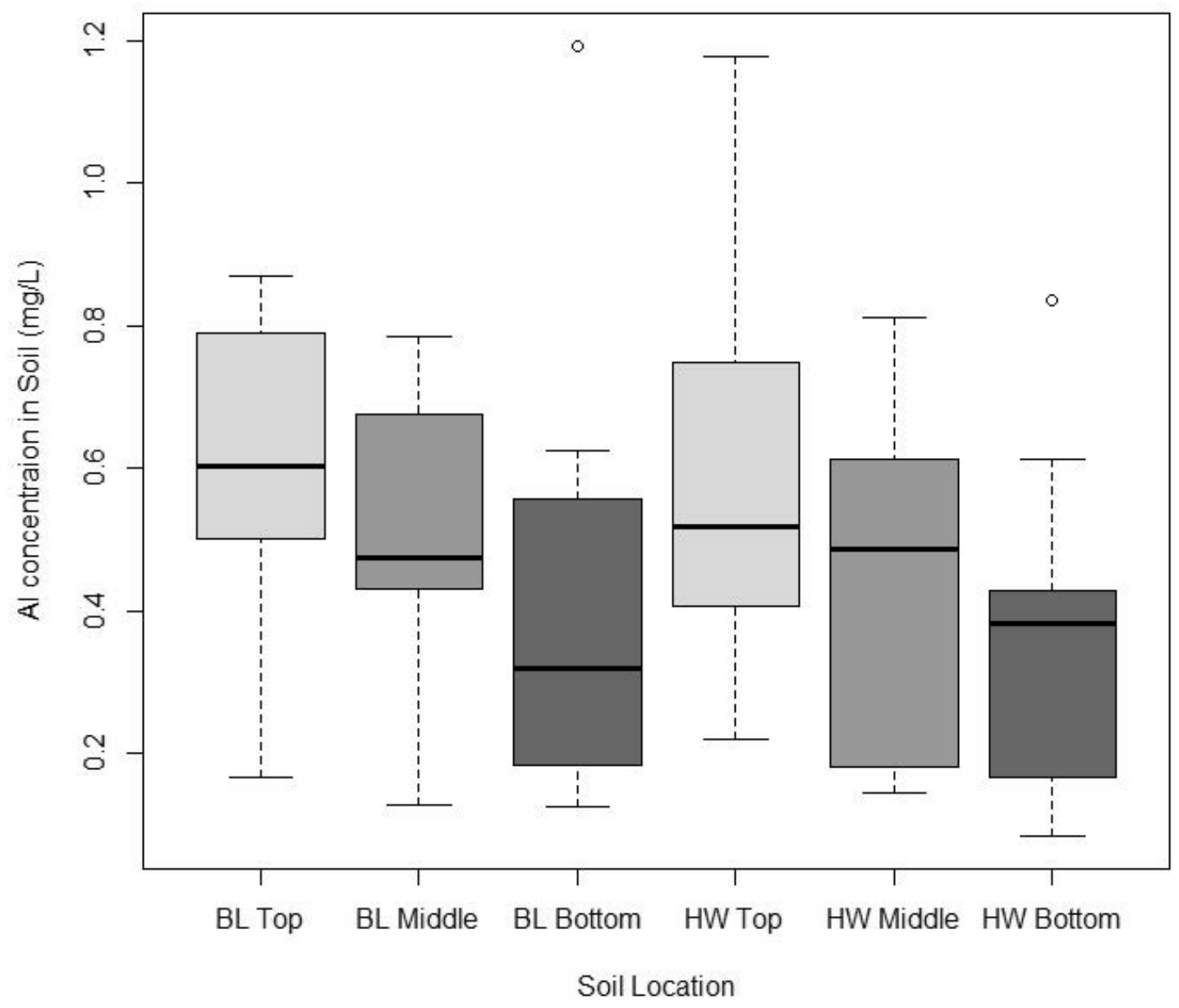

Figure 10: Aluminum concentrations in the soil layers of black locust (BL) and native hardwood (HW) stands. 

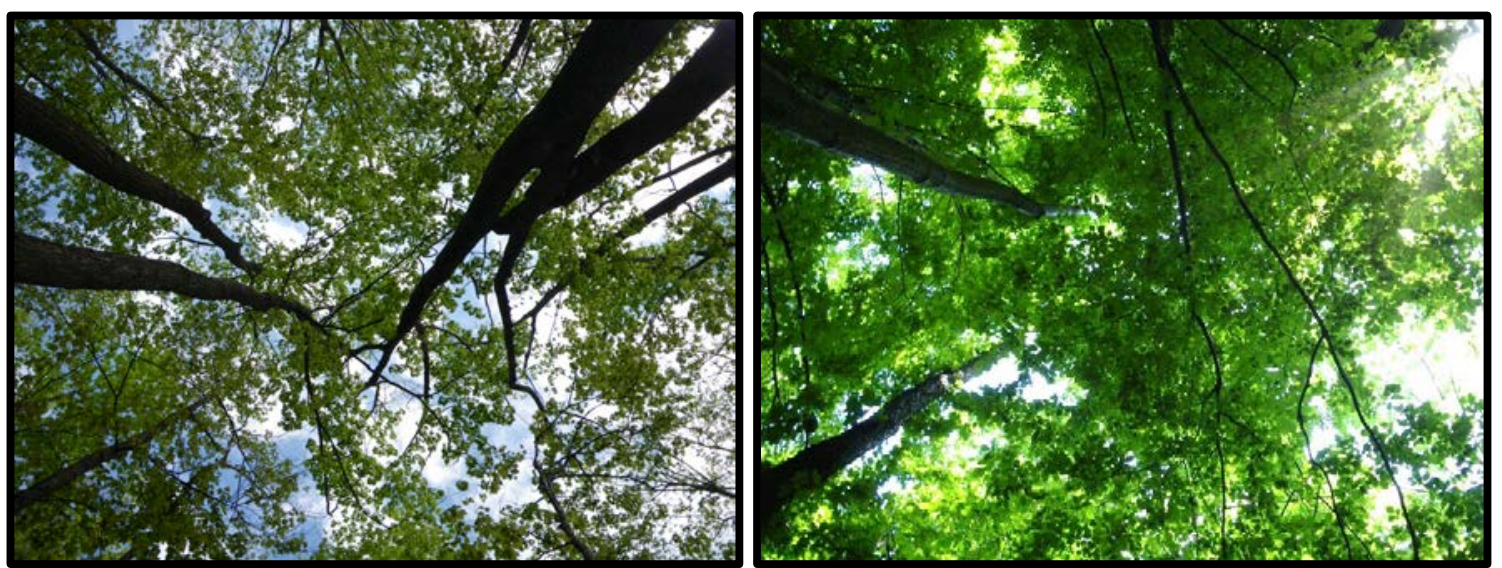

Figure 11: Differences in cover and light availability under black locust canopy (left) and native hardwood canopy (right) on June 22, 2011. Site Location: 677 North. 


\section{Appendix I:}

\section{A Brief History: Settlement of the Sleeping Bear Dunes Region (from Haswell and Alanen, 1994)}

The first Euro-American settlers arrived in the Sleeping Bear area in the 1840s, primarily for the forest resources and the area's prime location near the Great Lakes' shipping lanes. The area provided shelter and fuel for the growing amount of steamers on the lakes, South Manitou Island being the last natural harbor before Chicago where ships of all sizes could shelter and ride out inclement weather. Early settlers to the area were woodcutters and merchants, selling cordwood to steamers, and shipping fish and berries collected by the local Native Americans. The lumber industry soon reached the region and communities sprang up around the lumber docks and sawmills.

Drawn by the boom in economic activity, many settlers came from afar for the forest products industry, but also as part of Christianity missions. Primary means of transportation followed the waterways and beaches of the area, with roads not

prevalent in the area until the late 1860s. Many communities were formed at or close to the shore of Lake Michigan or on the many streams and rivers that lead to it.

After the Homestead Act of 1862, more settlers came to the area. The Homestead Act allotted up to 160 acres and required residence and land improvements for five years to claim the full title. From 1863-1923, 141 claims, for an average of 108 
acres each, were filed for areas within and immediately surrounding Sleeping Bear Dunes National Lakeshore.

By 1900, many of the forests in the area were depleted and the timber industry was drawing to a close. Thousands of settlers moved on and agriculture leapt to the forefront of the economic system. Farms went from subsidence farms to a means of making money, expanding in size and becoming more productive.

\section{Agricultural Methods}

From the 1840 s to the 1860 s, the primary method of agriculture practiced by Euro-Americans involved dragging a metal plowshare behind a draft animal. The products of their labor were primarily used by the farmer or for his animals; surplus could be traded or potentially sold at the markets by the water or the nearby villages. For early settlers, fields needed to be carved out of the thick forest, creating a land characterized by the small quintessential family farm among clearings in the trees.

Early crops included potatoes, corn, beans, a few varieties of grain, and maple sugar. The majority of soils are rated as marginal or sub-marginal for agriculture, and were it not for Lake Michigan's effect on the local climate, agriculture in the region would not have been as successful. Many settlers had a difficult time in the first years, often needing to buy what rare extras other settlers or Native Americans had. Much of the time was spent clearing and improving land, growing less labor-intensive crops, such as potatoes and corn, which were staples in their diets. Due to the early lack and 
primitiveness of the roads, farmers rarely had the opportunity to sell their surplus in a market setting. Instead, they sold their surplus to ships passing through.

The addition of transportation infrastructure created opportunities for more commercial agriculture and increased trade. The boom of the forest products industry provided local demand for crops, both for human and animal consumption. By 1880, steamships began to burn coal and no longer needed to stop and refuel with cordwood. Agriculture increased as a means for people to support themselves. Fruit trees, having been cultivated and grown by the Native Americans before Euro-American settlement, were also popular and commonly grown on farms in the area. The area provided the perfect climate and soils for a wide variety of tree-based produce and there was a willing market in Chicago. Fruit from the Sleeping Bear region quickly became popular and known for its quality, being harvested later in the season, and subsequently having a longer shelf life than their counterparts grown further south.

Scientific agricultural methods such as soil conservation and fertilization were virtually unheard of in the early days. With the exception of a few fruit tree experiments and trials in the late 1880 s, scientific farming was slow to come to the area. The expertise and knowledge from the Michigan Agricultural College was first applied to orchards, by way of pesticides and fungicides. By the late 1920s, Benzie County's agricultural extension agent was noting a rise in abandoned farms, indicative of a depletion of soil fertility. Thus, a variety of soil management techniques were introduced and employed at this time. Previous abuses from the logging era, and the 
nature of the soil itself (high acidity and low organic matter) led extension services to emphasize fertilizing and $\mathrm{pH}$ modifications, including growing nitrogen-fixing alfalfa and applying marl, a locally available source of lime.

\section{Conclusions}

The slow march of progress across the region helped shape both the landscape and the history of Sleeping Bear Dunes National Lakeshore. The impact of the forest products era left much of the land cut over and abused. The second-growth forests have grown up among the contours and remnants of the abandoned industry, evident by rusted and abandoned equipment scattered among the leaf litter and trees growing around ancient barbed wire. The short-lived agricultural era, eeked out on marginal soil, also left behind legacies of fruit trees now surrounded by deciduous trees, rock piles from plowing the fields, crumbling foundations, and exotic plants (Figure 12). 


\section{Figures}

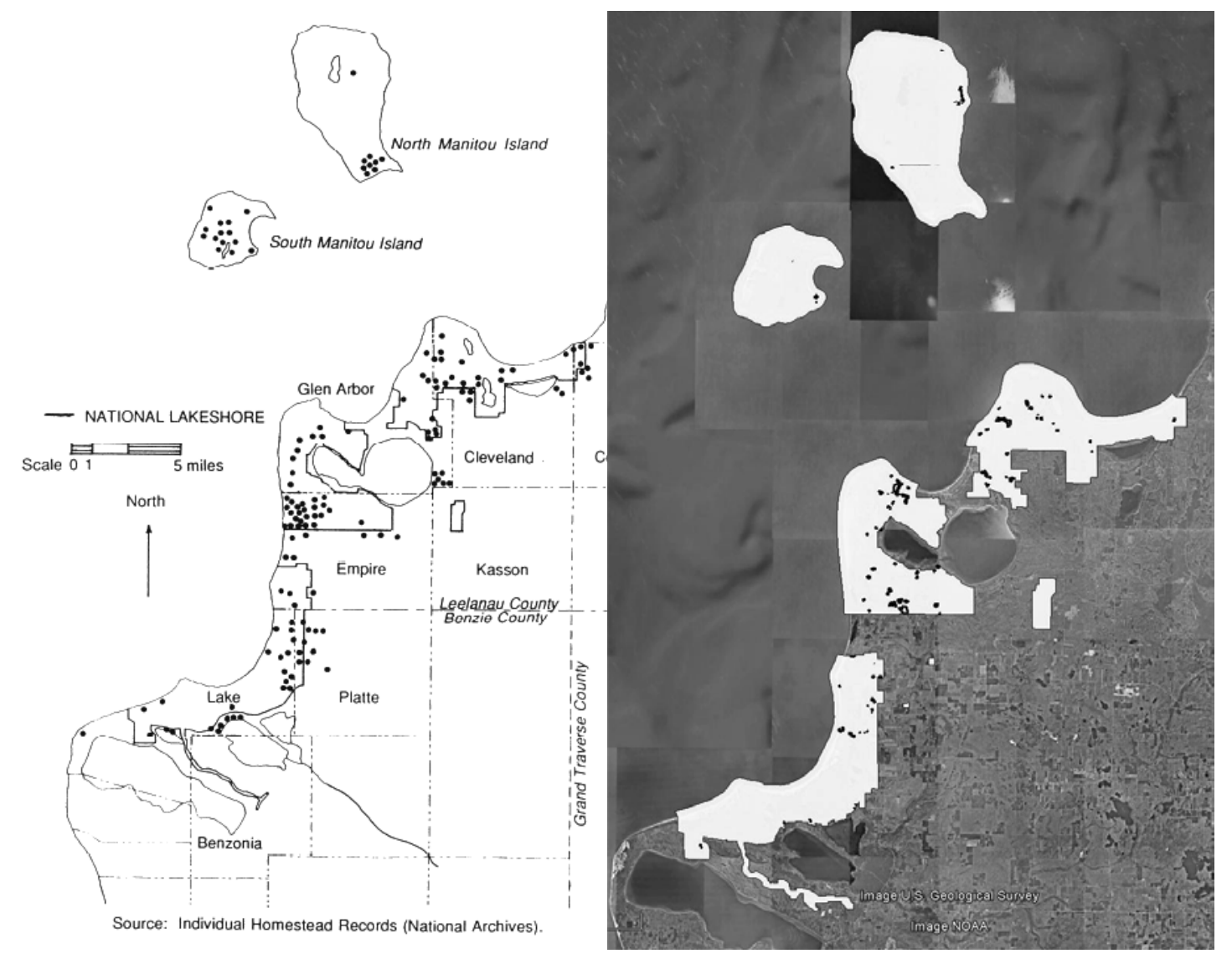

Figure 12: Comparison of homestead locations (1863-1923) within the Sleeping Bear Dunes National Lakeshore area and locations of known invasive tree infestations. Homestead figure from Haswell and Alanen, 1994. Image: C2013 Google. Invasive tree shapefiles from the NPS. 



\section{Appendix II:}

\section{Plot Locations}

\section{Shell Lake}

The Shell Lake location was perhaps the most unique of any of the plot locations. The black locust stand at this site is bordered by a field, a road, northern hardwood forest, and a pine plantation (Figure 13). What old land-use records could be found recorded this land as previous cattle-grazing fields. Black locust and hardwood plots were 170 m apart, across a clearing to match approximate landscape features and forest types noted in the black locust stand. Other features of Shell Lake include a large foundation within the stand boundaries, an abandoned cross-cut saw, and barbed wire between the black locust stand and a pine plantation. The NPS measured the area of the infestation as 0.91 ha in 2007.

\section{Hooper Road}

Hooper Road was removed from county roads used today and located in the forest near Valley View walk-in campground. The old roadbed or driveway is evident, making up part of the trail to the area. After a split in the trail, one continues and the other has gullied and formed a deep ravine. In the black locust stand, there are several foundations near the center of the infested area. Other anthropogenic changes in the area included an old water pump, a rustic hunting blind, and the nearby campground. The stand borders a field to one side and a white pine dominated area on another. NPS 
measured the black locust area to be 1.51 ha in size (Figure 14). Approximately 75 meters away from the black locust plot, the native hardwood plot was set on the other side of a large dip in the landscape. The hardwood plot contained a potentially rare species of Botrychium, which unfortunately could not be identified to species.

\section{Miller Hill Complex}

The Miller Hill complex contains the Miller Hill A, B, and C locations. At 3.68 ha total, it was untouched and seemed a prime location for multiple plots. Each 'lobe' of the black locust infestation touched a slightly different hardwood forest community (Figure 15); Miller Hill A had had more white pine, B had more oak prevalent, and C was close to a homesite. This Miller Hill complex had at least one sunken foundation, an old driveway scar and a clearing that was infested with black locust visibly smaller than the rest of the stand. Miller A location was classified as dry-mesic with prevalent white pine and bracken fern. The plot locations were $120 \mathrm{~m}$ apart. Miller B was located the furthest from the road, and was immediately adjacent to typical northern hardwood forest and an old driveway. The hardwood stand associated with Miller B was $160 \mathrm{~m}$ from the locust location. Potential plot locations within the closer hardwoods were located on slopes, and there was an open scrub area between the black locust and other hardwood stands, causing the paired stands to be further apart. Miller $\mathrm{C}$ was closest to the foundations, and had a more open black locust canopy. Apple trees were also prevalent in the immediate area. The paired locations were $85 \mathrm{~m}$ apart. 


\section{Narrows A \& B}

Narrows $A$ and $B$ are named for the narrow connection between Big and Little Glen Lakes (Figure 16). Narrows A is a heavily shaded stand 2.0 ha in size, that is used by the locals as a vegetation refuse dumping site. This has led to a large number of invasive and exotic species, particularly in the areas that receive more light. In the center of the stand, the large trees and heavy canopy prevent much of the understory from forming. The hardwood plot location is higher in elevation than the black locust plot, and further from the lake in an area populated with large big-toothed aspen and other native hardwood species. Fixed-area plots were 100 m apart.

Narrows B is located nearby next to the local cemetery and a pine plantation. The area is 0.66 ha in size and has rusted barbed wire fence and refuse of a bygone era. Other trees in the area are cherry and apple, suggesting it may have been a rudimentary orchard at one time. The paired hardwood location is located across the street on the same soil type, and is a beech-maple forest with large trees. A paired hardwood plot location on the same side of the street was not possible due to sloping lands and pine plantations. Paired plots were $160 \mathrm{~m}$ apart.

\section{North \& South}

The 677 location is characterized by several foundations and an old well that has been sealed. The entire infestation is 2.96 ha in size. To the northeast of the black locust stand are the remnants of an old field succeeding into forest. Old fence posts and rock 
piles are still evident (Figure 17). 677 North is located on top of a hill occupied by the black locust stand where large diameter trees begin to get smaller. There are rock piles at both plot locations that were spaced $130 \mathrm{~m}$ apart. $677 \mathrm{~S}$ was on the downhill side of the black locust stand and paired with a hardwood study plot with similar sloping characteristics. At the black locust fixed-area plot, barbed wire fence and old wire was found. The two locations were 100 m away. 


\section{Figures}

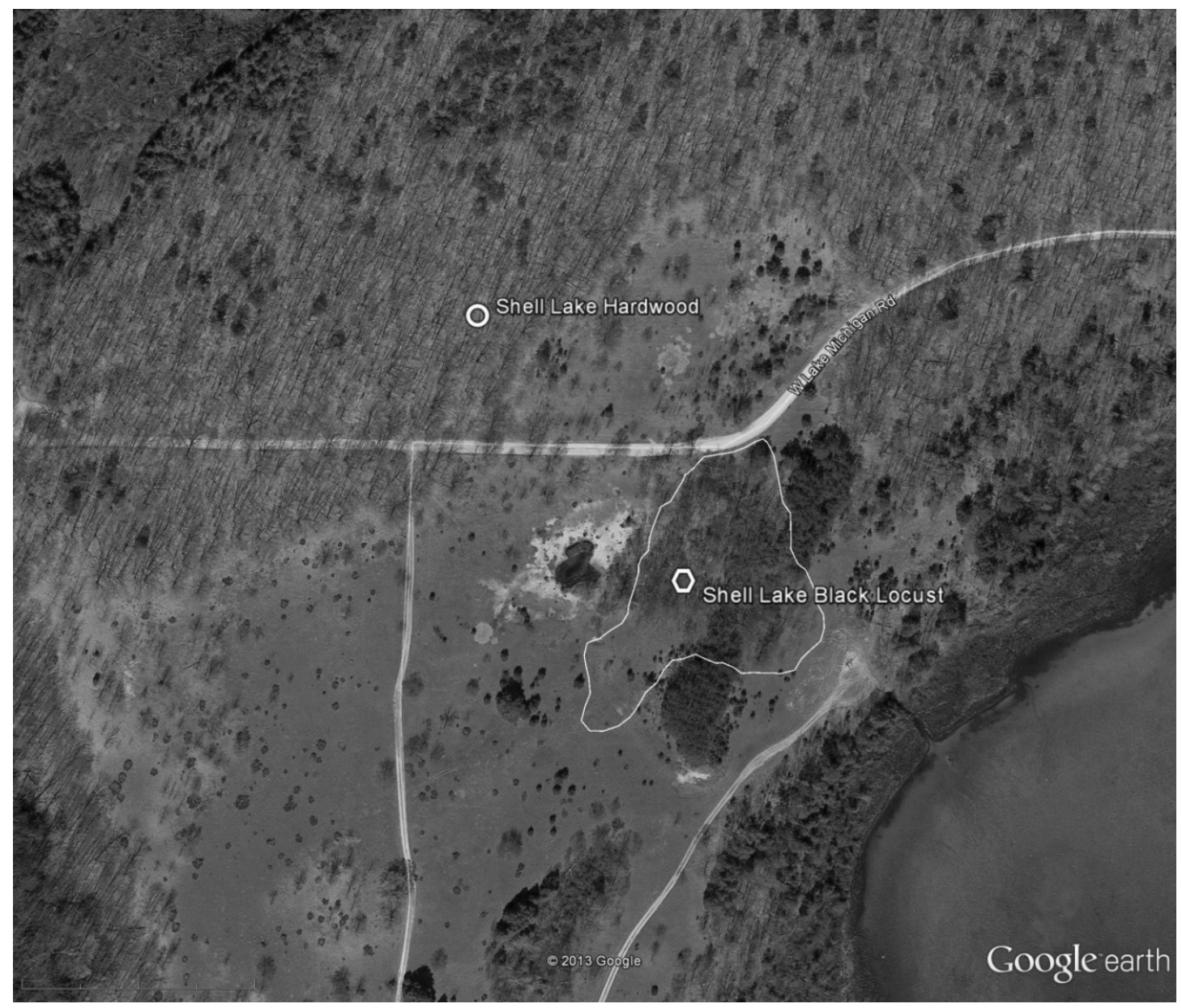

Figure 13: Aerial image of the Shell Lake plots. The boundary of black locust growth is just under a full hectare. Image: (C2013 Google. 


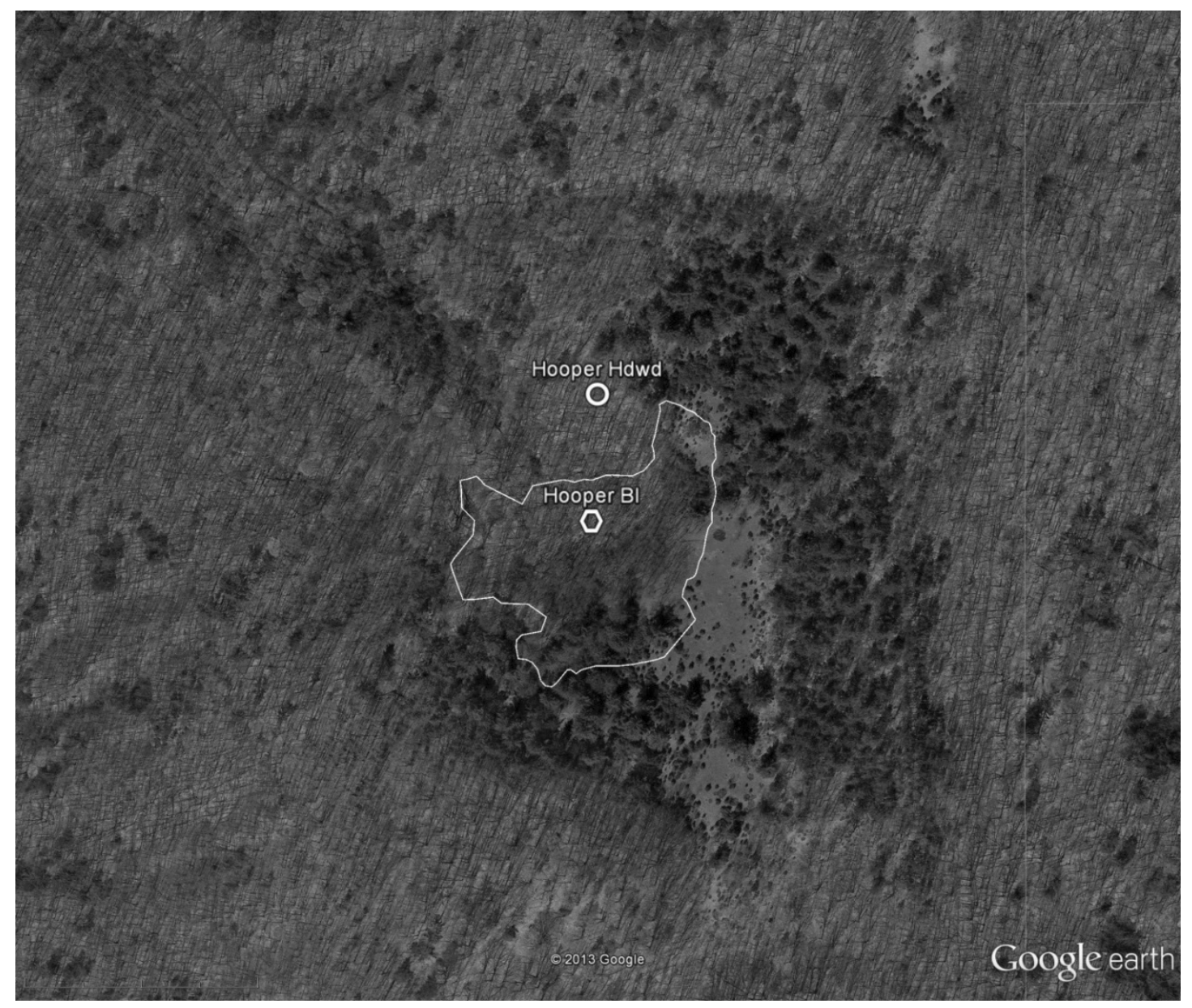

Figure 14: Aerial view of Hooper Road plot location. The faint line to the right is the NPS boundary line and Valley View walk-in campground is at the lower end of the clearing. Image: (C2013 Google. 


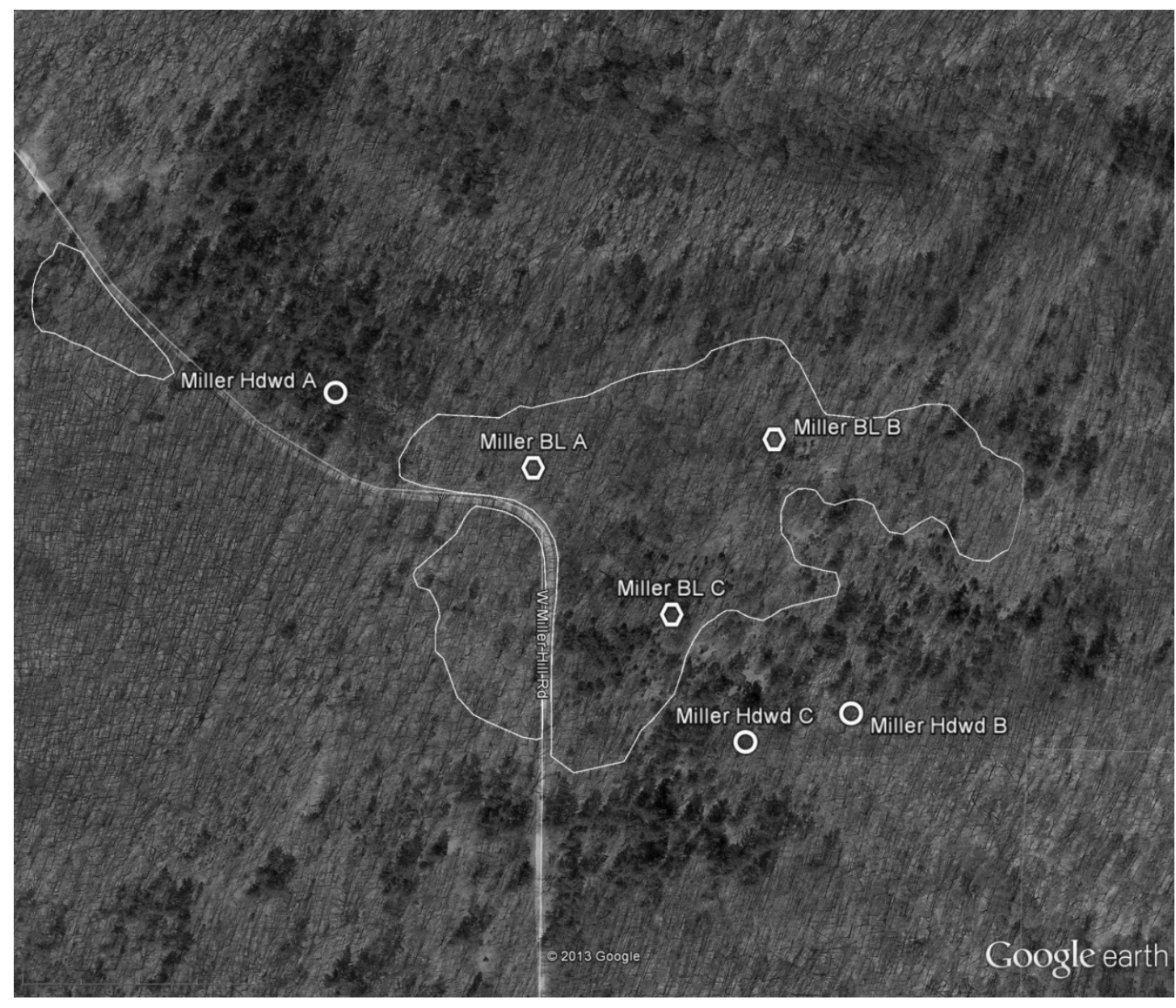

Figure 15: Miller Hill complex. The sampled location was the largest of the three stands in the area. Image: (C)2013 Google. 


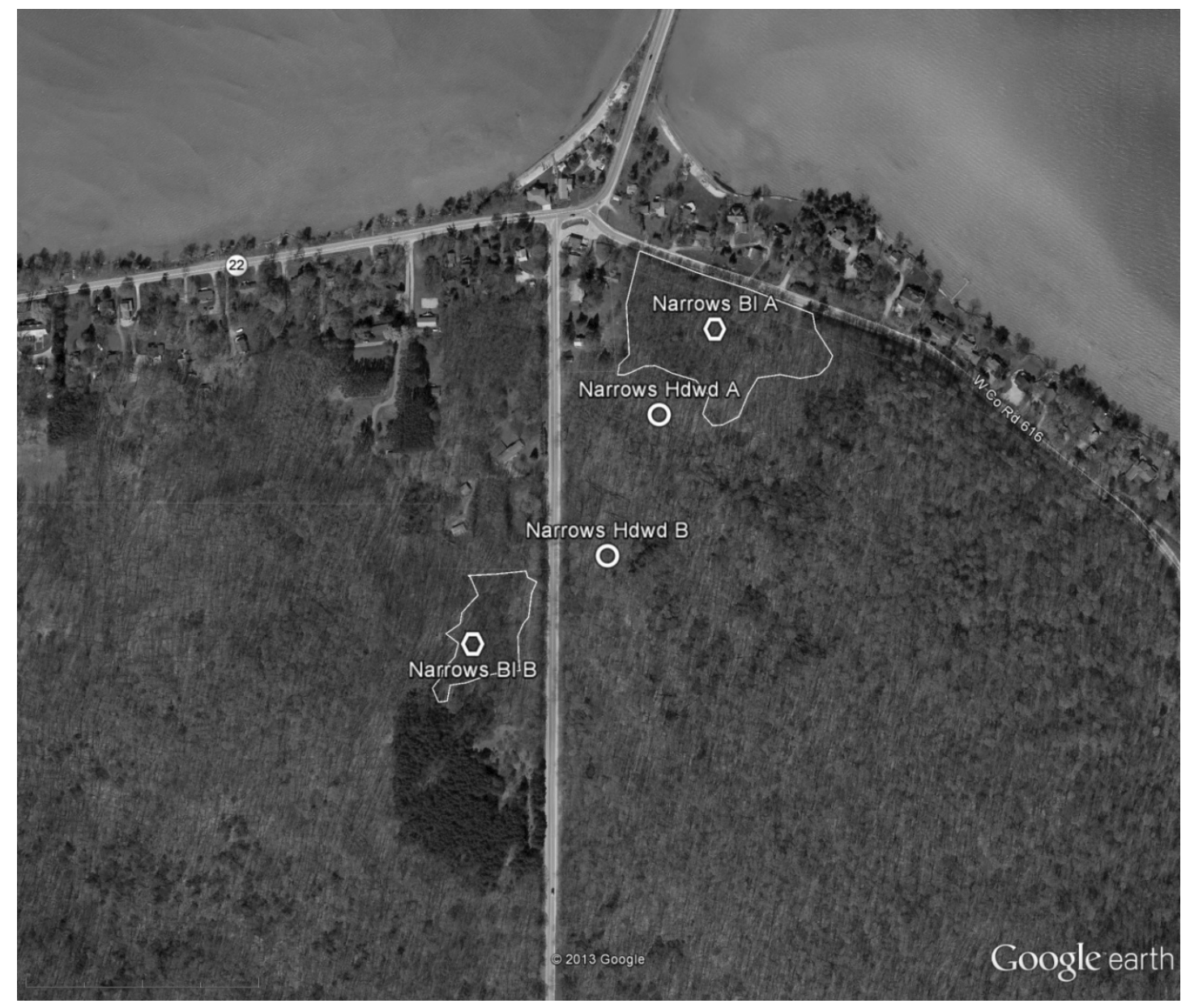

Figure 16: Locations of Narrows A and B. National Park boundaries form at least one edge of both of these stands. Narrows A is still heavily used by the locals as a yard refuse dumping site. Image: (C2013 Google. 


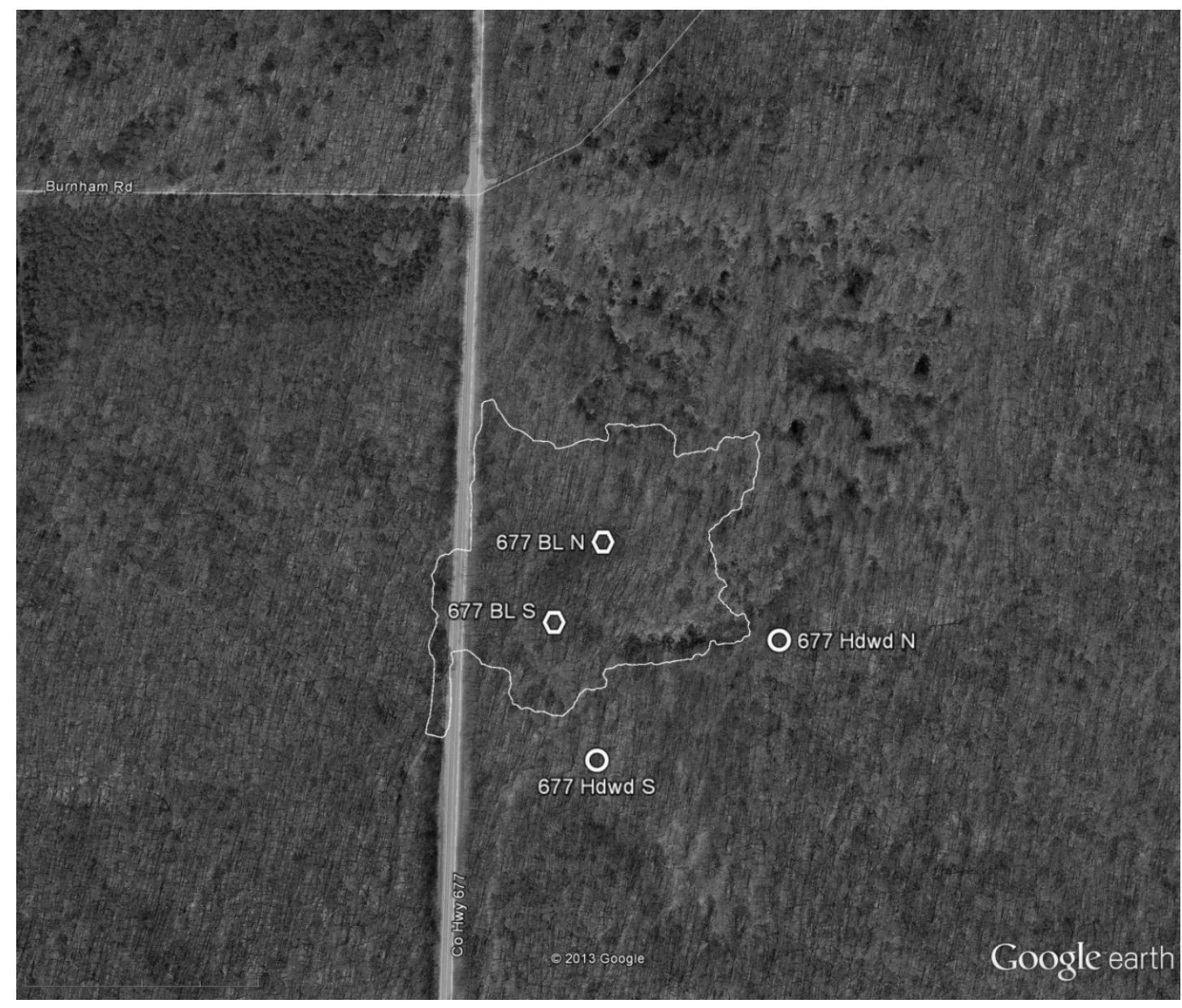

Figure 17: 677 location, one large black locust stand with evidence of anthropogenic disturbances. Image: (C2013 Google. 


\section{Appendix III:}

\section{Source Permissions}

Figure 1: USDA Forest Service. 2001. Locust leafminer, Odonatata dorsalis (Thunb.) (Pest Alert). NA-PR-01-01. Newton Square, PA: U.S. Dept. of Agriculture, Forest Service, Northern Area State \& Private Forestry. Created by federal employee and considered to be in the public domain.

Figure 2: (02013 Google: Left image: NOAA. Right image: NOAA, (2013 TerraMetrics, CCnes/Spot Image. Statement of Use: Imagery used in compliance with terms outlined in Google Earth EULA and under the Terms and Conditions of Use*.

Figure 12: Left image: Haswell and Alanen, 1994. Statement of Use: This material was funded by and for the use of the U.S. Department of the Interior and the State of Michigan and is considered to be in the public domain. Right image: (C2013 Google, Image U.S. Geological Survey, Image NOAA. Statement of Use: Imagery used in compliance with terms outlined in Google Earth EULA and under the Terms and Conditions of Use*.

Figure 13: (C2013 Google. Statement of Use: Imagery used in compliance with terms outlined in Google Earth EULA and under the Terms and Conditions of Use*.

Figure 14: (C2013 Google. Statement of Use: Imagery used in compliance with terms outlined in Google Earth EULA and under the Terms and Conditions of Use*.

Figure 15: (C2013 Google. Statement of Use: Imagery used in compliance with terms outlined in Google Earth EULA and under the Terms and Conditions of Use*.

Figure 16: (C2013 Google. Statement of Use: Imagery used in compliance with terms outlined in Google Earth EULA and under the Terms and Conditions of Use*.

Figure 17: (C2013 Google. Statement of Use: Imagery used in compliance with terms outlined in Google Earth EULA and under the Terms and Conditions of Use*.

*Permission guidelines found under the Google Permission Guidelines website at: http://www.google.com/permissions/geoguidelines.html. Accessed on June 02, 2013. 